PNL-6607

UC-510

$6 B$

A Research Report for Westinghouse Hanford Company

\title{
Comparison of Silver Sorbents for Application to Radioiodine Control at the PUREX Process Facility Modification
}
R. D. Scheele
L. L. Burger
B. T. Halko

September 1988

Prepared for the U.S. Department of Energy under Contract DE-AC06-76RLO 1830

Pacific Northwest Laboratory Operated for the U.S. Department of Energy by Battelle Memorial Institute 


\title{
DISCLAIMER
}

This report was prepared as an account of work sponsored by an agency of the United States Government. Neither the United States Government nor any agency thereof, nor Battelle Memorial Institute, nor any or their employees, makes any warranty, expressed or implied, or assumes any legal liability or responsibility for the accuracy, completeness, or usefulness of any information, apparatus, product, or process disclosed, or represents that its use would not infringe privately owned rights. Reference herein to any specific commercial product, process, or service by trade name, trademark, manufacturer, or otherwise does not necessarily constitute or imply its endorsement, recommendation, or favoring by the United States Government or any agency thereof, or Battelle Memorial Institute. The views and opinions of authors expressed herein do not necessarily state or reflect those of the United States Government or any agency thereof.

\author{
PACIFIC NORTHWEST LABORATORY \\ operated by \\ BATTELLE MEMORIAL INSTITUTE \\ for the \\ UNITED STATES DEPARTMENT OF ENERGY \\ under Contract DE-AC06-76RLO 1830
}

Printed in the United States of America
Available from
National Technical Information Service
United States Department of Commerce
5285 Port Royal Road
Springfield, Virginia 22161
NTIS Price Codes
Microfiche A01
Printed Copy

Pages
$001-025$
$026-050$
$051-075$


R. D. Scheele

L. L. Burger

B. T. Halko

September 1988

Prepared for the U.S. Department of Energy under Contract DE-ACO6-76RLO 1830

Pacific Northwest Laboratory

Richland, Washington 99352 



\section{SUMMARY}

In continued support of the design of the gaseous radioiodine control system for the PUREX (a) Process Facility Modification (PFM), the Pacific Northwest Laboratory (PNL) conducted laboratory-scale measurements of the performance of four state-of-the-art sorbents for radioiodine in the dissolver offgas (DOG) of a nuclear reprocessing plant. The PFM is a new head-end treatment $\mathrm{plant}$ being designed by Westinghouse Hanford Company (WHC) for the PUREX Plant at the Hanford Site.

The experiments performed measured the iodine effluent concentration from Norton silver mordenite (NAgZ), Linde silver mordenite (LAgZ), Linde silver faujasite ( $\mathrm{AgX})$, and silver nitrate-impregnated silicic acid $\left(\mathrm{AgNO}_{3} \mathrm{Si}\right)$ during simulated normal operating conditions in the PFM after three shutdown/ startup cycles, and during standby. At normal operating conditions the input gas is expected to have a dew point of $35^{\circ} \mathrm{C}$ to $40^{\circ} \mathrm{C}$ and contain $0.1 \mu \mathrm{mol} \mathrm{I} / \mathrm{L}$, 1 vol\% $\mathrm{NO}$, and 1 vol\% $\mathrm{NO}_{2}$. The sorbent bed would be at $150^{\circ} \mathrm{C}$. A shutdown/ startup cycle consisted of eliminating iodine and $\mathrm{NO}_{\mathrm{X}}$ from the input gas, cooling the bed to room temperature, stopping gas flow, and restarting the system. During standby conditions the input gas contained no iodine or $\mathrm{NO}_{x}$, the dew point was at $30^{\circ} \mathrm{C}$ to $35^{\circ} \mathrm{C}$, and the bed temperature remained at $150^{\circ} \mathrm{C}$.

Experimental studies reported in 1987 by this laboratory (Scheele and Burger 1987) showed that silver mordenite was capable of reducing the iodine concentration in a simulated PFM offgas to $<10^{-5} \mu \mathrm{mol} \mathrm{I} / \mathrm{L}$, which is an acceptable level of performance for the PFM. However, these studies used an input iodine concentration that was higher than expected in the process, which left some concern about silver mordenite's performance at process levels. To alleviate this concern and to determine if other state-of-the-art iodine sorbents would be acceptable substitutes, WHC requested that PNL perform a long-term ( 2 to 3 months) iodine trapping study using the iodine concentration in the PFM'S DOG.

(a) Purex and Uranium Recovery by EXtraction. The facility is located at the Hanford Site in southeastern Washington state, and is operated for the U.S. Department of Energy by the Westinghouse Hanford Company. 
This experimental study showed that $20 \mathrm{~cm}$ beds of NAgZ, LAgZ, and $18 \mathrm{wt} \%$ silver AgX could load up to $0.25 \mathrm{mmol} \mathrm{I} / \mathrm{g}$ sorbent and routinely reduce the iodine concentration in a simulated PFM DOG from $0.1 \mu \mathrm{mol} \mathrm{I} / \mathrm{L}$ to less than the target level of $10^{-5} \mu \mathrm{mol} \mathrm{I} / \mathrm{L}$. In contrast, the $\mathrm{AgNO}_{3} \mathrm{Si}$ unexpectedly failed to achieve this required level of performance, reducing the concentration on a routine basis only to $10^{-4}$ to $10^{-2} \mu \mathrm{mol} \mathrm{I} / \mathrm{L}$.

Standby and shutdown/startup cycling did not appear to affect the effluent concentration from the zeolite beds. It is possible that the shutdown/ startup cycle did affect the performance of the $\mathrm{AgNO}_{3} \mathrm{Si}$. Following the second shutdown/startup cycle with this bed, the effluent iodine concentration increased to $10^{-2} \mu \mathrm{mol} \mathrm{I} / \mathrm{L}$. Another increase occurred following the third shutdown/startup cycle, but could have been due to normal variation for the $\mathrm{AgNO}_{3} \mathrm{Si}$ system. It is possible that the $\mathrm{AgNO}_{3} \mathrm{Si}$ beds were exposed to condensed water prior to the first shutdown/startup, and this might have reduced their trapping ability.

The pressure drop measurements across the beds after exposure to the acidic gases of the PFM DOG and sorption of iodine indicate that all of the materials tested are sufficiently resistant to chemical degradation to be useful up to an iodine loading of $0.25 \mathrm{mmol} \mathrm{I} / \mathrm{g}$ sorbent. This was especially encouraging for the sorbent AgX, which had the potential of not being resistant to the combined $\mathrm{NO}_{x}$ and water in the DOG.

Since the mechanism for iodine trapping by silver-containing materials is not understood, it is difficult to identify purchasing specifications that would ensure adequate performance. Reasonable specifications for purchase of material would include zeolite type, form, mesh, and silver content. Chemical analyses to confirm specifications could be performed. Simple laboratory tests might be appropriate, although first it would be necessary to develop the test, then correlate the test results with both adequate and inadequate performance levels. Such tests might involve sorption of iodine from a solvent or from the gas phase.

In terms of monitoring the iodine content in the effluent from both the primary and secondary sorbent beds, collection of iodine in/on an iodine sorbent followed by gamma and $x$-ray counting of the sorbent sample appears to 
be an acceptable method. Collecting a sample for $8 \mathrm{~h}$ from a $500 \mathrm{~mL} / \mathrm{min} \mathrm{slip}$ stream would provide a reasonable measurement of the ${ }^{129} \mathrm{I}$ content in the gas stream at $10^{-5} \mu \mathrm{mol} \mathrm{I} / \mathrm{L}$.

Although this experimental study did show that the silver zeolites NAgZ, LAgZ, and AgX can load to $0.25 \mu \mathrm{mol} \mathrm{I} / \mathrm{L}$ and effectively reduce the iodine concentration from process levels to the target level, the materials were not tested to their full loading capacity. A study to determine the performance of these materials over their useful lifetimes would be worthwhile. The unexpectedly poor performance of $\mathrm{AgNO}_{3} \mathrm{Si}$ relative to the zeolites and a lack of an explanation for the comparative performances further emphasizes the need to understand the mechanism of iodine trapping. The chemistry of trapping by silver nitrate should be the most straightforward to predict and understand. Fundamental studies such as suggested by Scheele and Burger (1987) may be required to provide the necessary information. 


\section{ACKNOWLEDGEMENTS}

We would like to thank E. D. Waters and R. M. Orme of WHC for their insight on experimental design and their moral and financial support. We are a1 so grateful to J. L. Swanson for peer reviewing the report, D. W. Johnson for typing the report, R. B. Sinclair for his photography, and C. A. Hudgens for preparing the graphics. We are especially grateful to J. Fürrer for providing the $\mathrm{AgNO}_{3} \mathrm{Si}$ and pertinent performance information. 
$\checkmark$

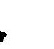

. 


\section{CONTENTS}

SUMMARY . . . . . . . . . . . . . . . . . . . . .

ACKNOWLEDGEMENTS ......................... . . vii

INTRODUCTION . . . . . . . . . . . . . . . . . . . . 1

CONCLUSIONS AND RECOMMENDATIONS . . . . . . . . . . . . . 3

EXPERIMENTAL DESIGN, APPARATUS, ANALYTICAL METHODS, AND

PROCEDURE .............................. 5

EXPERIMENTAL DESIGN . . . . . . . . . . . . . . . 5

APPARATUS USED FOR EXPERIMENTS . . . . . . . . . . . . 8

ANALYTICAL METHODS ................... 13

EXPERIMENTAL PROCEDURE . . . . . . . . . . . . . . 15

RESULTS . . . . . . . . . . . . . . . . . . . 17

TRAPPING AND STANDBY PERFORMANCE . . . . . . . . . . . . 17

Norton Silver Mordenite ............... 18

Linde Silver Mordenite ............... 24

Linde Silver Faujasite . . . . . . . . . . . 26

Silver Nitrate-Impregnated Silicic Acid . . . . . . . 30

PRESSURE DROP . . . . . . . . . . . . . . . . 36

QUALITY ASSURANCE TESTING OPTIONS . . . . . . . . . . . . . . 39

IODINE MONITORING . . . . . . . . . . . . . . . . . 41

REFERENCES .......................... 43 


\section{FIGURES}

1 Silver Sorbents Used in the Performance Tests . . . . . . . 6

2 Schematic of Experimental Apparatus . . . . . . . . . 9

3 Gas Delivery and Control System . . . . . . . . . . . 10

$4 \mathrm{NO}_{2}$ Generator, $\mathrm{H}_{2} \mathrm{O}(\mathrm{g})$ Generator, and Exit Flowmeters . . . . 10

5 Constant Temperature Oven, Beds, $I_{2}(g)$ Generator, and Condensate Traps ..... . . . . . . . . . 11

6 Beds, Preheater, and Effluent Sample Trap Assembly . . . . . . 11

7 Effluent Concentrations from NAgZ Beds as a Function

of Iodine Loading . . . . . . . . . . . . . . . . . 19

8 Effluent Concentrations from NAgZ Beds as a

Function of Time ................... . . . 21

9 Effluent Concentrations from LAgZ Bed 9 as a Function 25

10 Effluent Concentrations from LAgZ Bed 9 as a

11 Effluent Concentrations from $18 \mathrm{wt} \% \mathrm{Ag}$ AgX Beds as a Function of Iodine Loading . . . . . . . . . . . . 27

Effluent Concentrations from 18 wt\% $\mathrm{Ag} \mathrm{AgX} \mathrm{as} \mathrm{a}$
Function of Time . . . . . . . . . . . . . . . 28

Effluent Concentrations from $\mathrm{AgNO}_{3} \mathrm{Si}$ Beds as a
Function of Loading . . . . . . . . . . . . . . . 31

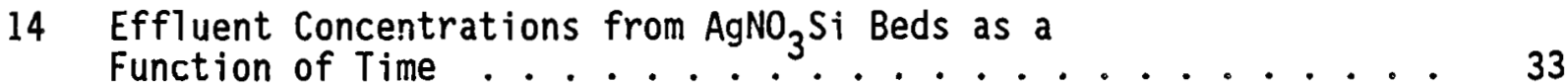




\section{TABLES}

1 Experimental Operating Conditions . . . . . . . . . . 7

2 Iodine Distribution on NAgZ Beds Before and After Standby . . . . . . . . . . . . . . . . 23

3 Iodine Distribution on LAgZ Bed Before
and After Standby . . . . . . . . . . . . . . . . . 26

4 Iodine Distribution on AgX Beds Before and After Standby................... 30

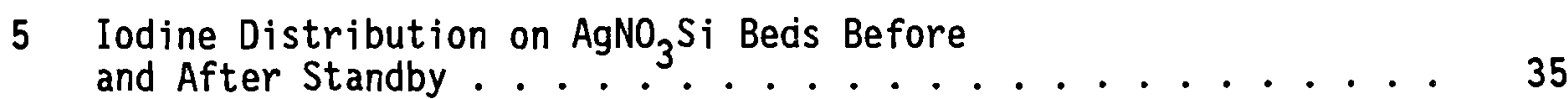

6 Pressure Drop Across Test Beds . . . . . . . . . . . . 37 


\section{INTRODUCTION}

Since 1980, Pacific Northwest Laboratory (PNL) has conducted work for Westinghouse Hanford Company (WHC) in support of the design of the radioiodine dissolver offgas (DOG) control system that would be used in the PUREX ${ }^{(a)}$ Process Facility Modification (PFM). Selected trapping methods for gaseous radioiodine were evaluated on a laboratory scale under normal process and off-normal conditions. The initial studies evaluated a combination of caustic scrubbing for the bulk of the iodine and Norton silver mordenite (NAgZ) for trapping the remaining elemental iodine and the organic iodides. (b) Subsequent work has focused on the study of solid sorbents. Scheele and Burger (1987) showed that a $12 \mathrm{~cm}$ bed of NAgZ could effectively reduce the gas concentration from $10 \mu \mathrm{mol} \mathrm{CH}_{3} \mathrm{I} / \mathrm{L}$ to less than $10^{-5} \mu \mathrm{mol} \mathrm{I} / \mathrm{L}$ at normal and off-normal conditions, while loading to $0.4 \mathrm{mmol} \mathrm{I} / \mathrm{g} \mathrm{NAgZ}$ at breakthrough. Scheele and Burger also showed that exposing loaded beds to the standby condition, which consists of flowing air without the presence of iodine or oxides of nitrogen in the input gas, stripped a portion of the trapped iodine from the bed. Additional testing showed that increasing bed length improved loading at breakthrough and variations in input concentration in the range 0.4 to $10 \mu \mathrm{mol} \mathrm{I} / \mathrm{L}$ did not impact the loading or effluent concentration.

Using the results of the previously conducted work, E. D. Waters and R. M. Orme of WHC determined that the performance of NAgZ met the requirements of the PFM radioiodine control system. To confirm that NAgZ could perform as expected under process conditions and to determine a suitable substitute or better material, PNL evaluated NAgZ and other potential iodine sorbents under normal operating conditions using an iodine concentration of $0.1 \mu \mathrm{mol} \mathrm{I} / \mathrm{L}$ (Burger and Scheele 1983). The evaluations were conducted under conditions simulating startup, shutdown, and standby.

(a) Plutonium and Uranium Recovery by EXtraction. The facility is located at the Hanford Site in southeastern Washington state, and is operated for the U.S. Department of Energy by Westinghouse Hanford Company.

(b) Letter report to Rockwe11 Hanford Operations, L. L. Burger, R. D. Scheele, and C. L. Matsuzaki. 1983. PFM Iodine Removal Studies. Pacific Northwest Laboratory, Richland, Washington. 
The experimental program reported here involved tests of NAgZ, Linde silver mordenite (LAgZ), 50\% exchanged silver faujasite ( $\mathrm{AgX}$ ), and silver nitrate-impregnated silicic acid $\left(\mathrm{AgNO}_{3} \mathrm{Si}\right)$. The effluent iodine concentrations were measured during simulated normal operating conditions, after three shutdown/startup cycles, and during standby. Because of funding and timing constraints, the experiments could not be continued until breakthrough. Thus, the loading capacity of these materials at the process input iodine concentration was not determined. 


\section{CONCLUSIONS AND RECOMMENDATIONS}

The laboratory-scale experimental program described here demonstrated that $20 \mathrm{~cm}$ deep beds of NAgZ, LAgZ, and 18 wt\% silver AgX can effectively control gaseous iodine contained in a normally operating PFM DOG up to an iodine loading of $0.25 \mathrm{mmol} \mathrm{I} / \mathrm{g}$ sorbent. Performance of these zeolites is independent of whether the system has been operated continuously or shutdown and brought back into operation, or is in standby mode. This study also showed, by measurement of $\triangle \mathrm{P}$ across the beds, that the three sorbents are stable when exposed to the highly acidic gas representative of the PFM DOG and loaded to $0.25 \mathrm{mmol} \mathrm{I} / \mathrm{g}$ sorbent. In contrast, $\mathrm{AgNO}_{3} \mathrm{Si}$ failed to perform to the minimum requirements established for acceptable operation in the PFM.

of the three zeolites tested, the AgX had the best loading profile (shortest loading zone). Each of the zeolites appears to have a much higher useful loading capacity than reached in these experiments (i.e., $0.25 \mathrm{mmol}$ $I / g$ sorbent).

Since the mechanism for iodine trapping by silver-containing materials is not understood, it is difficult to identify purchasing specifications that would ensure adequate performance. Reasonable specifications for purchase of material include zeolite type, form, mesh, and silver content. Chemical analyses to confirm specifications could be performed. Simple laboratory iodine sorption tests might be appropriate, although the test would have to be developed and the results correlated with both adequate and inadequate performance levels. Such tests might involve sorption of iodine from a solvent or from the gas phase.

Collection of iodine in/on an iodine sorbent followed by gamma and $x$-ray counting of the sample appears to be an acceptable method for monitoring the iodine content in the effluent from both the primary and secondary sorbent beds. Collecting a sample for $8 \mathrm{~h}$ from a $500 \mathrm{~mL} / \mathrm{min}$ slip stream would provide a reasonable measurement of the ${ }^{129}$ I content in the gas stream at the target effluent concentration.

Until the mechanism of iodine trapping by silver-containing materials is more completely understood, we cannot be sure that the sorbent will always be 
effective. This is illustrated by the poor performance of the $\mathrm{AgNO}_{3} \mathrm{Si}$ in these experiments, which has been shown by others to be an excellent sorbent. There is at this time no suitable explanation for the failure of $\mathrm{AgNO}_{3} \mathrm{Si}$ to perform satisfactorily, while the silver zeolites performed very well and met process requirements. Basic chemistry studies such as those suggested by Scheele and Burger (1987) are still needed.

In addition, experiments like those reported here should be continued until the bed has been loaded to capacity using process level iodine input concentrations. Such experiments would be valuable for ensuring that the physical integrity of the sorbents will be maintained for their scheduled lifetime. To support development of acceptance criteria, tests should be developed to determine the adequacy of purchased sorbent material. 


\section{EXPERIMENTAL DESIGN, APPARATUS, ANALYTICAL METHODS, AND PROCEDURE}

The objective of the 1aboratory experimental program was to compare the performance of several state-of-the-art trapping materials for gaseous radioiodine under conditions expected in the PFM. In this section we discuss the experimental design, apparatus, and test methods.

\section{EXPERIMENTAL DESIGN}

These experiments provided the bases for comparing the performance of four sorbents developed for radioiodine control in a nuclear fuels reprocessing plant (FRP) (Burger and Scheele 1983). The experiments were designed to measure the sorbents' ability to trap process concentrations of iodine from a gas stream representative of the PFM DOG at normal operating conditions and when exposed to one or more shutdown/startup cycles. In addition, the chronic release level of iodine under standby conditions was determined. The experimental design also allowed us to determine whether loading the material with iodine or exposure to the highly acidic gas stream would impact the physical integrity of the materials.

Our extensive testing of NAgZ in support of the PFM project (Scheele and Burger 1987) made this zeolite the leading candidate for application in the PFM. However, it would be desirable to identify a substitute sorbent in the event NAgZ is no longer available. The Norton Company no longer manufactures mordenite, although a mordenite is available from Linde. Alternatives include several solid materials that have demonstrated an ability to effectively trap iodine from simulated DOG streams. Thomas et a1. (1977) at the Idaho National Engineering Laboratory (INEL) demonstrated the utility of fully exchanged AgX (36 wt\% silver) and AgZ (18 wt\% silver). As McKay, Miquel and White (1982) describe, the work of Wilhelm, Fürrer and others of Karlsruhe indicated that $\mathrm{AgNO}_{3} \mathrm{Si}$ could effectively trap iodine in a DOG.

Based on information in the literature, the materials selected for testing were AgZ (18 wt\% silver) prepared from Norton mordenite Zeolon 900 (NAgZ), AgZ (18 wt\% silver) prepared from Linde mordenite (LAgZ), partially exchanged silver faujasite (AgX) (18 wt\% silver) prepared from Linde 13X, and silver 
nitrate-impregnated silicic acid $\left(\mathrm{AgNO}_{3} \mathrm{Si}\right)$. For comparison 18 wt\% silver AgX, prepared so the silver was uniformly distributed throughout the material, was used instead of the fully exchanged AgX. Fully exchanged AgX has a silver content of $36 \mathrm{wt} \%$. Figure 1 presents the four materials, plus the $36 \mathrm{wt} \%$ silver AgX used in the sampler traps.

The three zeolites were sized $-20+40$ mesh. WHC selected this particle size based on the work of Scheele and Burger (1987), which showed acceptable pressure drops across beds of $-20+40$ mesh NAgZ, and Scheele, Burger, and Matsuzaki (1983), which showed that trapping efficiency increased with a decrease in particle size. Presized silver-exchanged zeolites were purchased from Ionex Corporation. The $\mathrm{AgNO}_{3} \mathrm{Si}$ was used at its manufactured size of 1.6-mm-dia. beads. $\mathrm{Dr}$. J. Fürrer of Karlsruhe provided the $\mathrm{AgNO}_{3} \mathrm{Si}$ since the material was not commercially available unless purchased in very large quantities. Ionex Corporation prepared the $18 \mathrm{wt} \%$ silver $\mathrm{AgX}$ so that the $\mathrm{Ag}$ was evenly distributed throughout the AgX particles.

In the original experimental design we $\mathrm{planned}$ to test three replicate beds of $\mathrm{NAgZ}, \mathrm{AgX}$, and $\mathrm{AgNO}_{3} \mathrm{Si}$. However, $\mathrm{LAgZ}$ was also tested because of the potential shortage of NAgZ. Because NAgZ was the leading candidate for application in the PFM and the non-zeolite $\mathrm{AgNO}_{3} \mathrm{Si}$ was previously shown to be

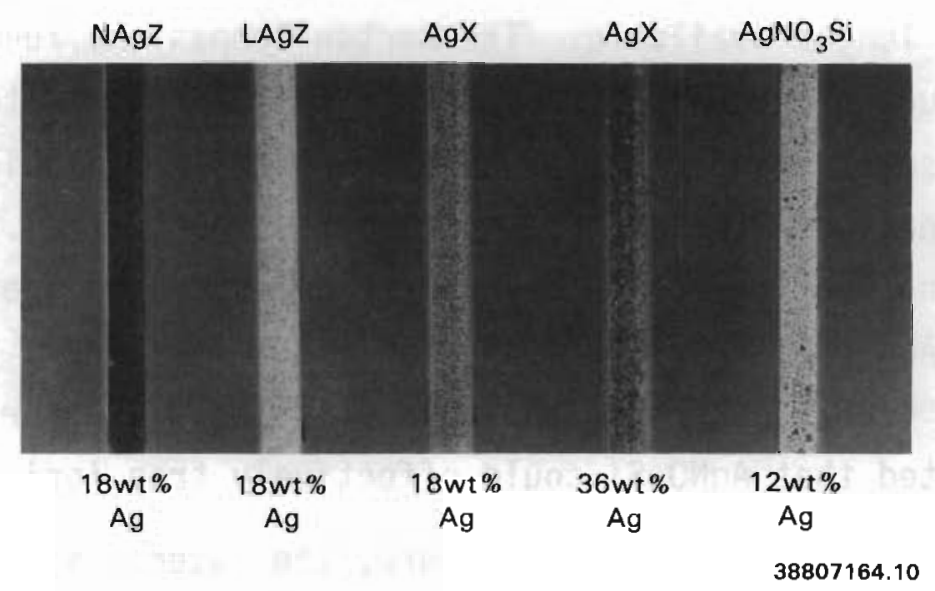

FIGURE 1. Silver Sorbents Used in the Performance Tests 
effective for this application, three beds of these materials were tested. The AgX could be susceptible to degradation in the highly acidic environment of an FRP, so one bed of LAgZ was substituted for one bed of AgX.

The experiments were performed at the PFM operating and standby conditions expected to exist in the PFM, as shown in Table 1. The effluent samplers were replaced every 2 weeks. Approximately every 4 weeks a shutdown and startup test was performed. During normal operation of the PFM, a bed of AgZ will last about 1 year and may be exposed to one or more shutdown and startup cycles. During shutdown gas will not flow through the beds and the bed heaters will be turned off. In our tests, shutdown and startup tests were accomplished in an $8 \mathrm{~h}$ day. The effluent gas sampler was left in place until the air flow was stopped. Samplers were not installed for the shutdown and startup tests. During standby there was no iodine or $\mathrm{NO}_{x}$ in the input gas, the bed was $150^{\circ} \mathrm{C}$, and the dew point was maintained at 30 to $35^{\circ} \mathrm{C}$.

\section{TABLE 1. Experimental Operating Conditions}

\begin{tabular}{|c|c|c|}
\hline \multirow[b]{2}{*}{ Operating Parameter } & \multicolumn{2}{|c|}{ Level } \\
\hline & Normal Operation & Standby Operation \\
\hline Gas Composition & & \\
\hline N0, vol\% & 1 & 0 \\
\hline $\mathrm{NO}_{2}, \mathrm{vol} \%$ & 1 & 0 \\
\hline $\mathrm{H}_{2} \mathrm{O}$, vol\% & 6 & 6 \\
\hline $\mathrm{H}_{2} \mathrm{O}, \mathrm{mmol} / \mathrm{L}$ & 2.5 & 2.5 \\
\hline $\mathrm{I}_{2}, \mu \mathrm{mol} \mathrm{I} / \mathrm{L}$ & 0.1 & 0 \\
\hline Air, vol\% & 89.4 & 91.5 \\
\hline
\end{tabular}

Bed Parameter

Length, cm

20

20

Diameter, cm

1

1

Face Velocity, $\mathrm{m} / \mathrm{min}$

5

5

Flow rate, L/min

0.4

0.4

Temperature, ${ }^{\circ} \mathrm{C}$ 
The nine beds were run in parallel, with the test materials distributed across the manifold to prevent experimental bias due to location. The NAgZ occupied positions 1,4 , and 7 (Figure 2), the $\mathrm{AgNO}_{3} \mathrm{Si}$ occupied positions 2, 5, and 8, the AgX occupied positions 3 and 6, and the LAgZ occupied position 9. At the end of the iodine loading experiment the beds were subjected to standby conditions for 7 days to determine the chronic release rate (see Table 1). The apparatus used for these experiments is described in the following section.

Due to budget and time constraints the experimental program was stopped after loading the $20 \mathrm{~cm}$ beds to approximately $0.25 \mathrm{mmol} \mathrm{I} / \mathrm{g}$ material, or $15 \%$ silver utilization.

\section{APPARATUS USED FOR EXPERIMENTS}

The experimental apparatus was designed to allow simulation of the expected normal conditions in the PFM in terms of superficial face velocity, sorbent particle size, water content in the gas stream, $\mathrm{NO}$ and $\mathrm{NO}_{2}$ concentrations, and temperature. A schematic of the laboratory apparatus is presented in Figure 2. The experimental apparatus consisted of the gas delivery and flow control system; the gaseous iodine generator; and the test beds, including temperature control (Figure 3 to 6 ).

The gas delivery and flow control system consisted of gas bottles, an oil-free air pump, mass flow controllers, rotameters, a gas holdup and mixing bulb for generation of $\mathrm{NO}_{2}$, a gaseous water generator, and a gas manifold to distribute the iodine-containing gas to each sorbent bed. Commercially produced gas bottles supplied purified grades of $\mathrm{O}_{2}$ and $\mathrm{N}_{2}$ and a technical grade (>99\% purity) of N0. The oil-free air pump provided air flow. During operation, the air was pumped into a ballast tank to eliminate variations in air pressure to the mass flow controller. Electronic mass flow controllers controlled the gas flows and floating-ball flowmeters verified the flows. The $\mathrm{NO}_{2}$ was prepared by mixing a stoichiometric amount of $\mathrm{O}_{2}$ with the $\mathrm{NO}$ in the $100 \mathrm{~mL}$ Pyrex bulb shown in Figure 4, thus providing a $50 \% \mathrm{NO} / 50 \% \mathrm{NO}_{2}$ mixture. The $\mathrm{glass}$ bulb was sized to provide sufficient residence time for ensuring conversion of the desired amount of $\mathrm{NO}$ to $\mathrm{NO}_{2}$. 


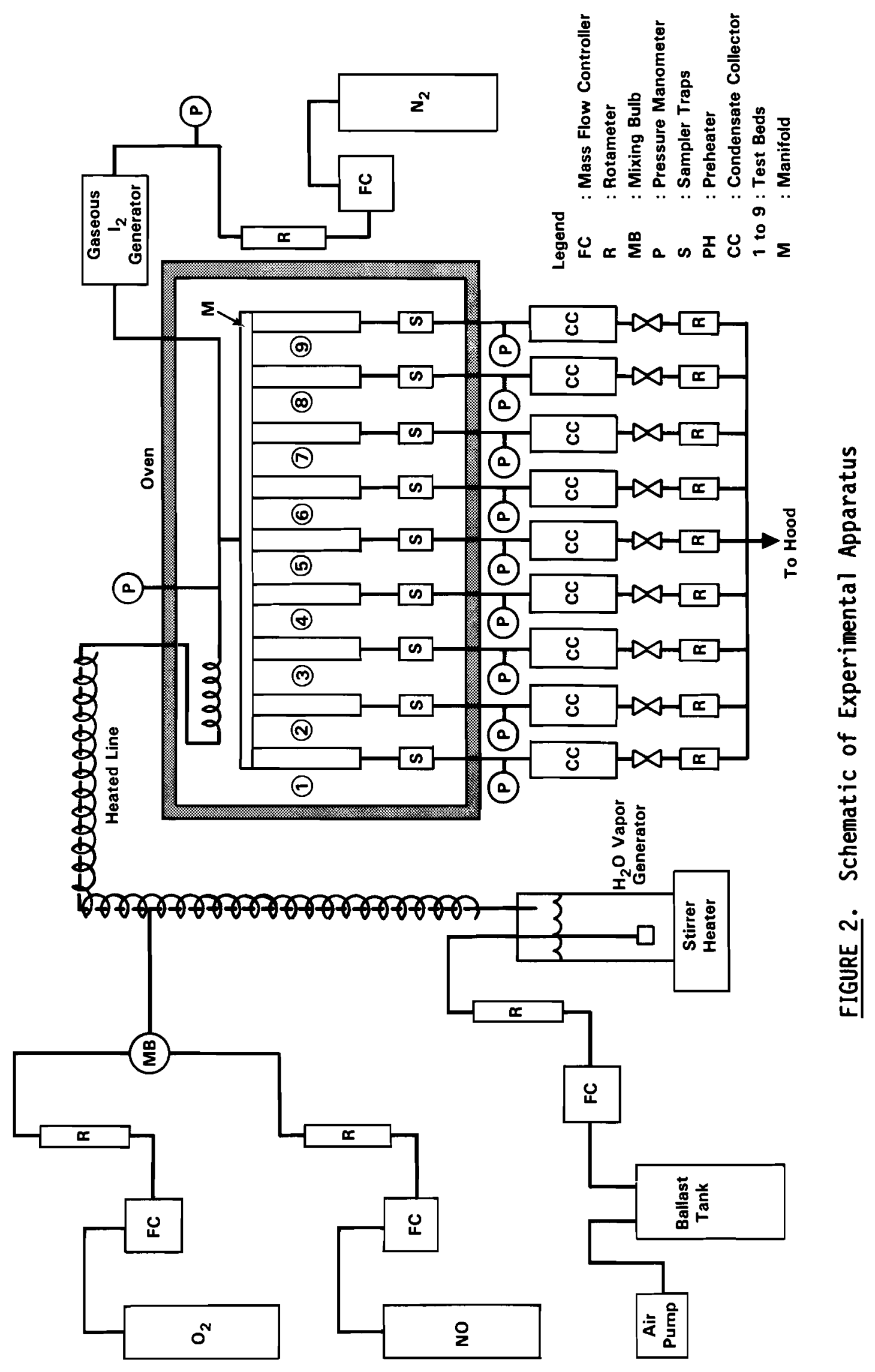




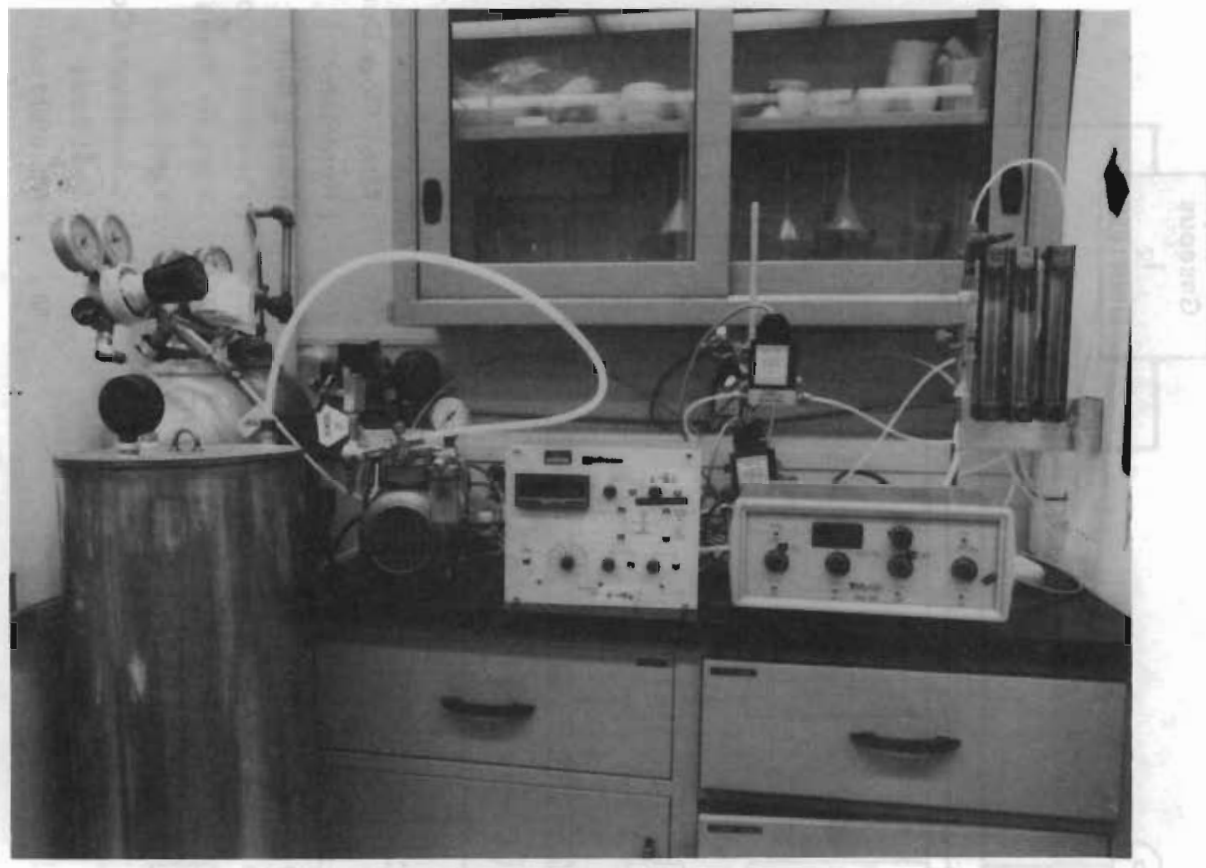

FIGURE 3. Gas Delivery and Control System

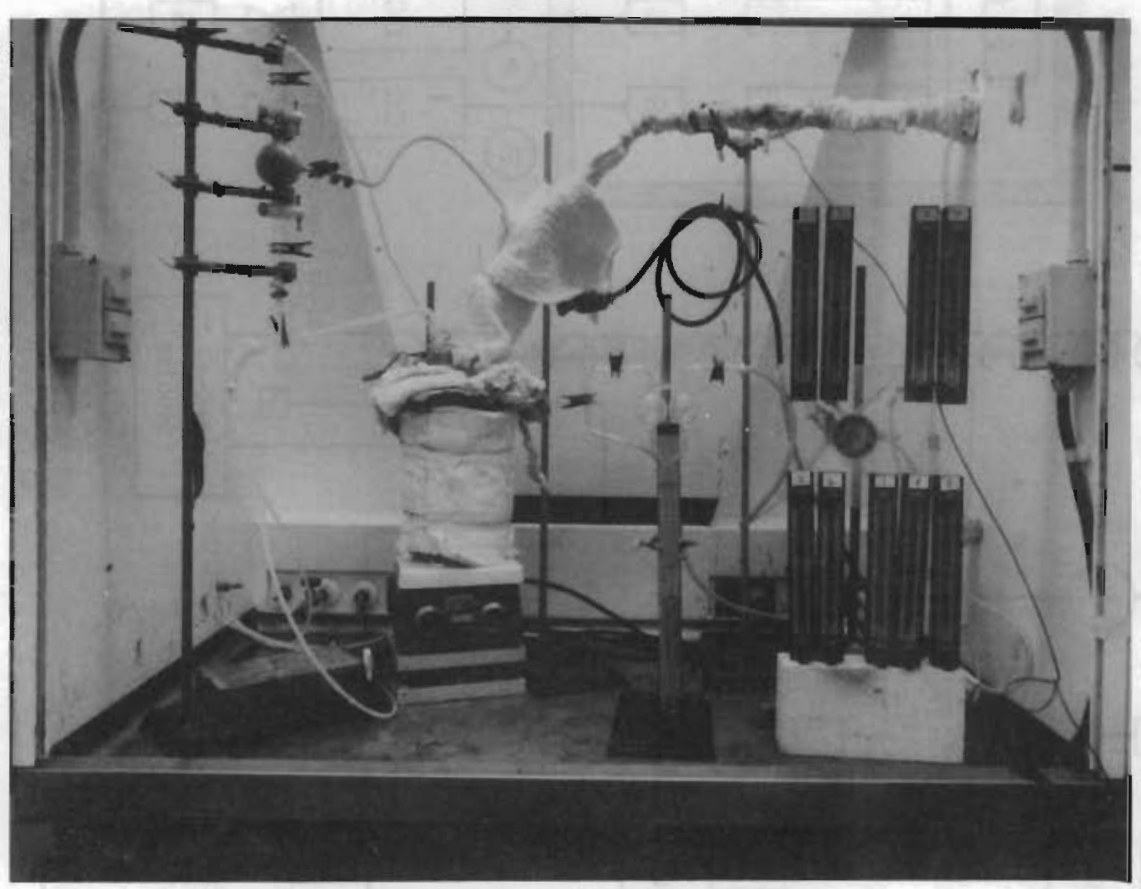

FIGURE 4. $\mathrm{NO}_{2}$ Generator, $\mathrm{H}_{2} \mathrm{O}(\mathrm{g})$ Generator, and Exit Flowmeters 


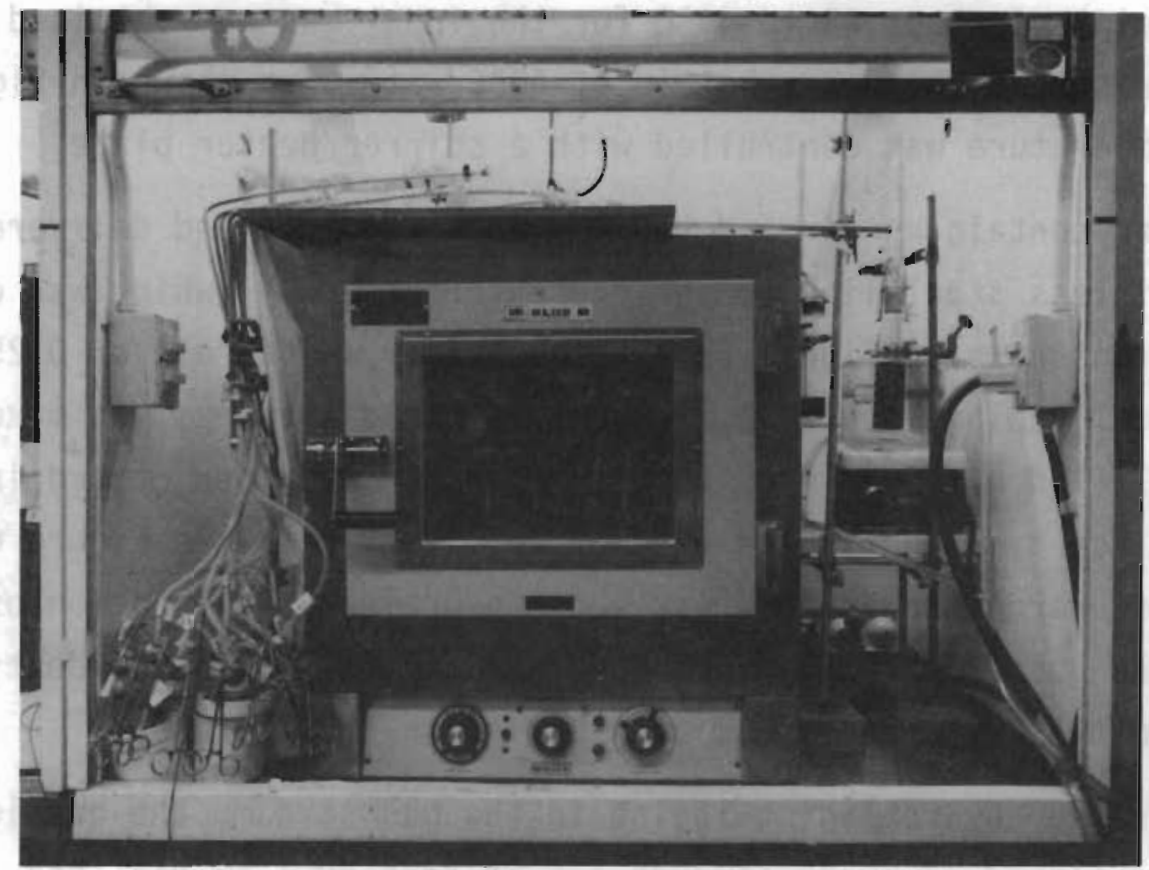

FIGURE 5. Constant Temperature Oven, Beds, $\mathrm{I}_{2}(\mathrm{~g})$ Generator, and
Condensate Traps

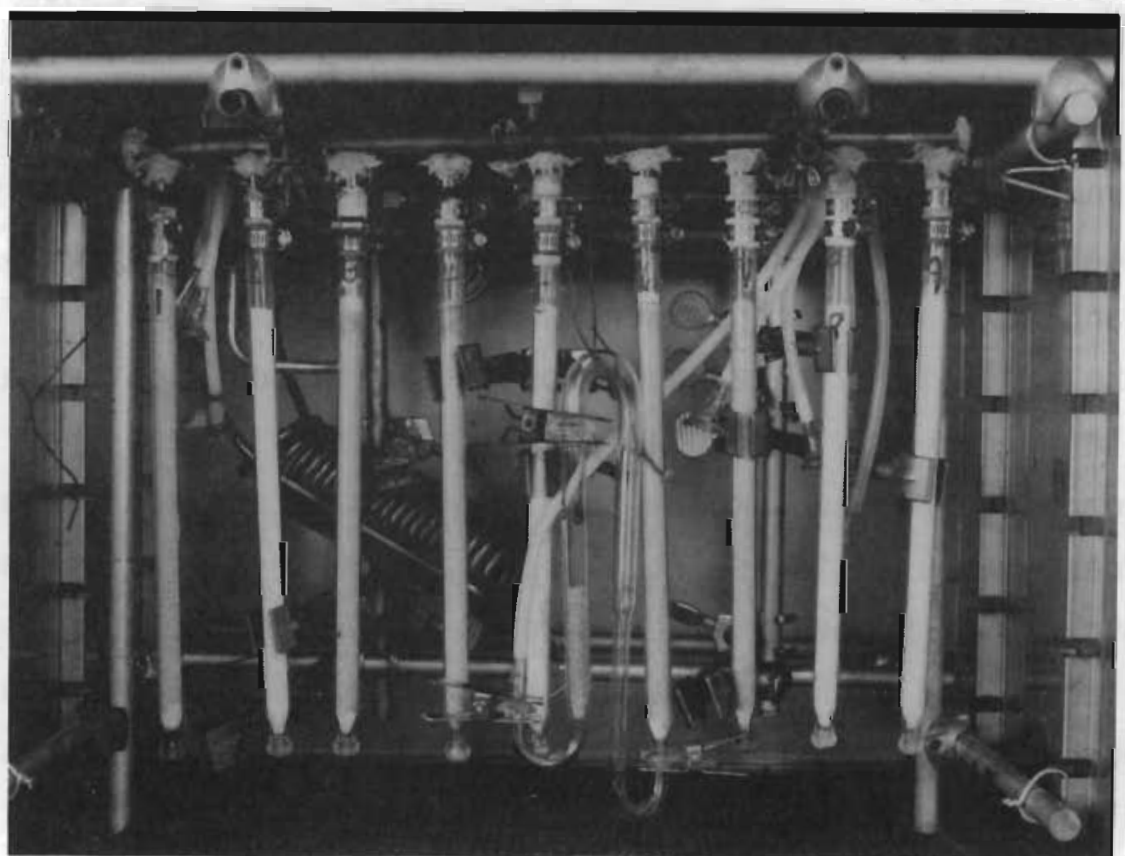

FIGURE 6. Beds, Preheater, and Effluent Sample Trap Assembly (beds are shown after loading and before standby) 
A dew point of about 35 to $40^{\circ} \mathrm{C}$ for the input gas was obtained by bubbling the air stream through a bottle of $40^{\circ} \mathrm{C}$ water, as shown in Figure 4. The water temperature was controlled with a stirrer/heater plate.

The water-containing air and the $\mathrm{NO}_{\mathrm{x}}$ were combined and delivered through a heated stainless steel line to the preheater assembly, which was contained within the oven shown in Figure 5. The preheater was a coil of $0.25-i n .-0 . D$. stainless steel tubing, shown in Figure 6 . This gas stream was mixed with the gaseous $\mathrm{I}_{2}-1$ aden stream from the $\mathrm{I}_{2}$ generator and then passed into the gas manifold for distribution to each of the test beds (see Figure 6 ). The gas flowed downward through the test beds to prevent fluidization of the bed material. The gas flow through each bed was controlled using identical rotameters on the exit lines from each bed shown in Figure 4.

To determine any remaining iodine in the gas stream, the gas leaving each test bed flowed downward through a 5 -cm-deep by 1 -cm-dia. bed of fully exchanged (36 wt\% Ag) AgX. The iodine collection trap and configuration is shown in Figure 6 . The iodine-free gas stream then left the oven and passed through condensed-1iquid collection traps before passing through the exit rotameters.

The gas delivery lines for the air, $\mathrm{N}_{2}$, NO, and $\mathrm{O}_{2}$ were plastic, and the exit line from the $\mathrm{NO}_{2}$ generator bulb was Teflon and glass. The gas lines beyond the water generator and the manifold were stainless steel. The bed containers and AgX sampler containers were borosilicate glass. The beds were joined to the manifold by butting the borosilicate tube to the manifold and using a Teflon sleeve and worm gear clamps to ensure a leak-free system. The beds were connected to the sampler tubes using ball and socket joints and silicone grease was used to seal the joints. Grease specifications indicated utility above $200^{\circ} \mathrm{C}$; however, after 2 weeks at $150^{\circ} \mathrm{C}$, the joints froze. Previous experience with high-temperature silicone grease at temperatures up to $230^{\circ} \mathrm{C}$ had been positive (Scheele and Burger 1987), and such grease would have been a more suitable choice.

Since elemental iodine is expected to be the predominant iodine species in the PFM DOG, $\mathrm{I}_{2}$ was selected as the chemical form of iodine to be used in this study instead of methyl iodide $\left(\mathrm{CH}_{3} \mathrm{I}\right)$, which was used in previous work 
(Scheele and Burger 1987). Methods used previously were not totally satisfactory for generating radiotraced $\mathrm{I}_{2}$ gas, particularly for extended operation (letter report, Burger, Scheele, and Matsuzaki 1983). Therefore, an alternate method was used that involved suspending solid elemental iodine in water and controlling the temperature, and thus the vapor pressure, of the elemental iodine.

To radiotrace the elemental iodine a mixture of solid $I_{2}$, water, iodide ion $\left(0.01 \mathrm{~mole} \mathrm{I}^{-} / \mathrm{mole} \mathrm{I}\right)$, and ${ }^{125} \mathrm{I}$ tracer as iodide ion was prepared and allowed to equilibrate for more than 4 weeks. Elemental iodine reacts rapidly with $\mathrm{I}^{-}$to form the triiodide ion, which presumably improves the isotopic exchange rate. Samples of the aqueous phase, plus gas samples from the bubbler described below, verified that exchange had occurred.

To deliver the gaseous $\mathrm{I}_{2}$ to the test beds, nitrogen was bubbled through a coarse frit submerged in the stirred, aqueous iodine/triodide suspension/ solution contained in a gas-bubbling bottle. The nitrogen supplied from a gas bottle carried the gaseous $I_{2}$ to the manifold, where it was mixed with the air $/ \mathrm{NO}_{\mathrm{x}}$ stream. The nitrogen flow was regulated by a mass flow controller and monitored using a rotameter. Preliminary testing demonstrated that the gaseous $\mathrm{I}_{2}$ generator, if operated at room temperature $\left(22^{\circ} \mathrm{C}\right)$, could consistently deliver the needed concentration of $\mathrm{I}_{2}$ to the manifold. The transfer line from the $\mathrm{I}_{2}$ generator was constructed of glass and stainless steel, and was as short as possible to limit $\mathrm{I}_{2}$ deposition. Preliminary testing indicated that $\mathrm{I}_{2}$ would pass quantitatively through $50 \mathrm{~cm}$ of $6.4-\mathrm{mm}-0 . D$. stainless steel tubing heated to $150^{\circ} \mathrm{C}$.

\section{ANALYTICAL METHODS}

To evaluate the performance of the iodine sorbents, the iodine concentration was periodically measured in both the effluent and $\mathrm{I}_{2}{ }^{-1}$ aden gas from the $\mathrm{I}_{2}$ generator. Chemical and radioanalytical methods were used for the analyses.

To chemically analyze the iodine in solutions of interest, we used an iodide ion Specific Ion Electrode (SIE). The method was applicable to determining the amount of iodine present in the caustic traps used to collect 
gaseous $I_{2}$ and in the $I_{2}$ generator itself. In this method hydroxylamine nitrate or sulfate was added to reduce all the higher oxidation states ( $\mathrm{I}_{2}$ and $\mathrm{IO}_{3}{ }^{-}$) present in solution to iodide. Nitric acid was used to adjust the $\mathrm{pH}$ to 2 and sodium nitrate was used to adjust the ionic strength of the solution.

This method was used in the developmental stages of the $I_{2}$ generator and later during the experiments to determine that the generator consistently delivered the desired amount of iodine to the test beds. A controlled flow of nitrogen was bubbled through the $I_{2}$ generator, then passed through a $1 \underline{M}$ caustic scrubber to remove the gaseous halogen. The caustic solution containing iodine was then analyzed to chemically determine the iodine content. Aliquots of the aqueous radiotraced iodine/triiodide slurry/solution were also analyzed to determine total iodine. The radioiodine content was then determined and the specific activity of the iodine was calculated.

The iodine was radiotraced with ${ }^{125}$ I at a nominal specific activity of $2 \mathrm{Ci} / \mathrm{mol} \mathrm{I}$. We analyzed for radioiodine using $\mathrm{NaI}(\mathrm{Tl})$ scintillation detectors. We used a well crystal to measure radioiodine in the effluent traps, samples of the iodine generator slurry, and caustic traps. Segmented bed counts were performed using a right circular cylindrical NaI(Tl) crystal. A lead shield with a $10 \mathrm{~cm}$ slit was placed between the crystal and the bed, thus permitting the bed to be counted in six slightly overlapping $35 \mathrm{~mm}$ segments.

A sample of ${ }^{125}$ I solution was submitted for standardization. We then used this standardized solution and dilutions of it to prepare ${ }^{125}$ I standards on $36 \mathrm{wt} \%$ silver AgX that contained varying amounis of ${ }^{125} \mathrm{I}$. The mean specific activity (cps/mol) and standard deviation (sd), based on the many analyses, were calculated. The sd was used to caiculate the confidence 1 imits for the effluent concentrations presented later.

The ${ }^{125}$ I standards on AgX were prepared by adding known amounts (20 to $500 \mu \mathrm{L}$ ) of standard solution, or dilutions of the solution, to the amount of AgX used in the iodine effluent sample traps. A few drops of standard solution were added to a layer of AgX, adding only enough to wet that layer without allowing the solution to contact the counting tube. A second layer 
of AgX was added and the process repeated until the standard al iquot was added to the AgX. The samples were air dried or dried in a vacuum oven at $70^{\circ} \mathrm{C}$. Replicate samples and standards were prepared by several people using different volumes of standardized solution.

To determine whether the sorbents were being chemically degraded or affected by exposure to the acids in the gas stream or by the sorption of iodine, the pressure drop across each bed was periodically measured using a mercury manometer. One side of the manometer was connected to the inlet side of the gas manifold and the other side was connected to the outlet side of each bed.

\section{EXPERIMENTAL PROCEDURE}

The experiments consisted of a loading stage and a standby stage. Three shutdown and startup tests were included in the loading stage. To start the system the oven was heated to $40^{\circ} \mathrm{C}$, when the air flow was started. When the oven stabilized at $150^{\circ} \mathrm{C}$, the $\mathrm{NO}_{X}$ and iodine flows were started. About twice a week the condensate traps were emptied. The pressure drops were measured each working day. Every 2 weeks the effluent AgX sample traps were removed and replaced. The ball and socket joints were regreased at each sampling and the system was leak-tested. After the third sampling all joints after the test beds were regreased. About every 4 weeks a shutdown and startup test was performed.

During the shutdown and startup tests, the iodine and $\mathrm{NO}_{x}$ flows were stopped and the oven was turned off and cooled to $40^{\circ} \mathrm{C}$. The air flow was then stopped and the oven cooled to room temperature. The AgX iodine sample traps were then replaced and the experiments restarted.

At the end of 67 days the system was shut down. The beds were removed from the oven and segment gamma counted, then returned to the oven for the standby test. Startup for the standby stage was the same as the loading stage except that no $\mathrm{NO}_{x}$ and $\mathrm{I}_{2}$ were present during the 7 -day standby test. 


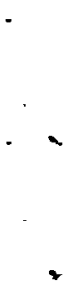

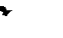




\section{RESULTS}

The zeolites NAgZ, AgX, and LAgZ generally performed better than expected as compared to previously conducted work using a higher feed concentration (Scheele and Burger 1987). Each material reduced the iodine concentration in the gas stream to $<10^{-5} \mu \mathrm{mol} \mathrm{I} / \mathrm{L}$. In these tests the $\mathrm{AgNO}_{3} \mathrm{Si}$ did not consistently meet the target criteria of $<10^{-5} \mu \mathrm{mol} \mathrm{I} / \mathrm{L}$ in the effluent.

The shutdown/startup cycle did not appear to affect the performance of the three silver zeolites, although the second shutdown/startup cycle may have affected the performance of the $\mathrm{AgNO}_{3} \mathrm{Si}$ beds. The effluent concentration from each $\mathrm{AgNO}_{3} \mathrm{Si}$ bed increased to $\$ 10^{-5} \mu \mathrm{mol} \mathrm{I} / \mathrm{L}$ following the second shutdown/startup cycle.

In general, standby operation also did not seem to affect the effluent concentration from any of the beds. The effluent concentration remained near the concentration measured during previous loading periods.

The following discussion presents more detailed information on the performance of each material during loading and standby, the effect of three shutdown/startup cycles, and the effects of iodine loading and exposure to a gas stream containing acidic ${ }^{\mathrm{NO}}{ }_{x}$ on the pressure drop across each of the beds.

\section{TRAPPING AND STANDBY PERFORMANCE}

In this section the trapping and standby performance of each material tested is presented graphically, with the iodine effluent concentration from the bed shown as a function of iodine loading and time. The distribution on the beds after loading and after standby is also presented.

The loading portrayed in the graphs and tablès is based on an input concentration of $0.1 \mu \mathrm{mol} \mathrm{I} / \mathrm{L}$, as measured during preliminary testing of the gaseous $\mathrm{I}_{2}$ generator and periodic measurement of the iodine generator output during the loading. Error limits at the $95 \%$ confidence level are also included. The error results from the sd of the standard and gamma counting of the sample. In some cases the lower limit was less than 0 and is shown on 
the figures as a line extending below the limits of the ordinate. The error limits reported in the tables are based solely on counting statistics and do not include variability due to bed placement during counting. The variance due to placement may account for some of the distribution changes observed for the beds after standby.

The mass transfer zone is typically defined as the length of bed that reduces the concentration of the species involved from its input value to some prescribed low value. The latter may cover a wide range, perhaps $10^{-2}$ or $10^{-5}$. Since in this study the iodine concentration cannot be measured within the bed, we adapted this method to obtain estimates of the mass transfer zone. The first and most analytically sensitive measurement uses the loading level measured on different segments of the test beds. The second measurement uses the color of the iodine-loaded test bed to define the transfer zone. In both cases the end of the transfer zone is defined as the point where the iodine loading falls to an arbitrary low level.

\section{Norton Silver Mordenite}

As shown in Figures 7 and 8 , NAgZ can reduce the iodine concentration from $0.1 \mu \mathrm{mol} \mathrm{I} / \mathrm{L}$ to less than the target concentration of $10^{-5} \mu \mathrm{mol} \mathrm{I} / \mathrm{L}$ up to loadings of $0.24 \mathrm{mmol} \mathrm{I} / \mathrm{g} \mathrm{NAgZ}$. Generally, the effluent concentration was $<10^{-6} \mu \mathrm{mol} \mathrm{I} / \mathrm{L}$. The concentration from bed 1 rose above $10^{-6} \mu \mathrm{mol} \mathrm{I} / \mathrm{L}$ only during standby.

Shutdown and startup cycles do not appear to impact the ability of NAgZ to trap gaseous iodine from a simulated DOG. The effluent iodine concentration rises or falls for the three beds in an apparently random fashion after the bed cycles through shutdown/startup.

Standby for 7 days also appears to have little or no effect on the effluent concentration from the bed. For bed 1 it increased to $10^{-6} \mu \mathrm{mol} \mathrm{I} / \mathrm{L}$ but remained below $10^{-6} \mu$ mol $\mathrm{I} / \mathrm{L}$ for beds 4 and 7 . Table 2, which presents the iodine distribution on each bed after loading and after standby, shows some downstream migration of the iodine. This suggests that if standby continued for a longer period, more iodine might have migrated from the beds. However, the information is insufficient for further conclusions. 


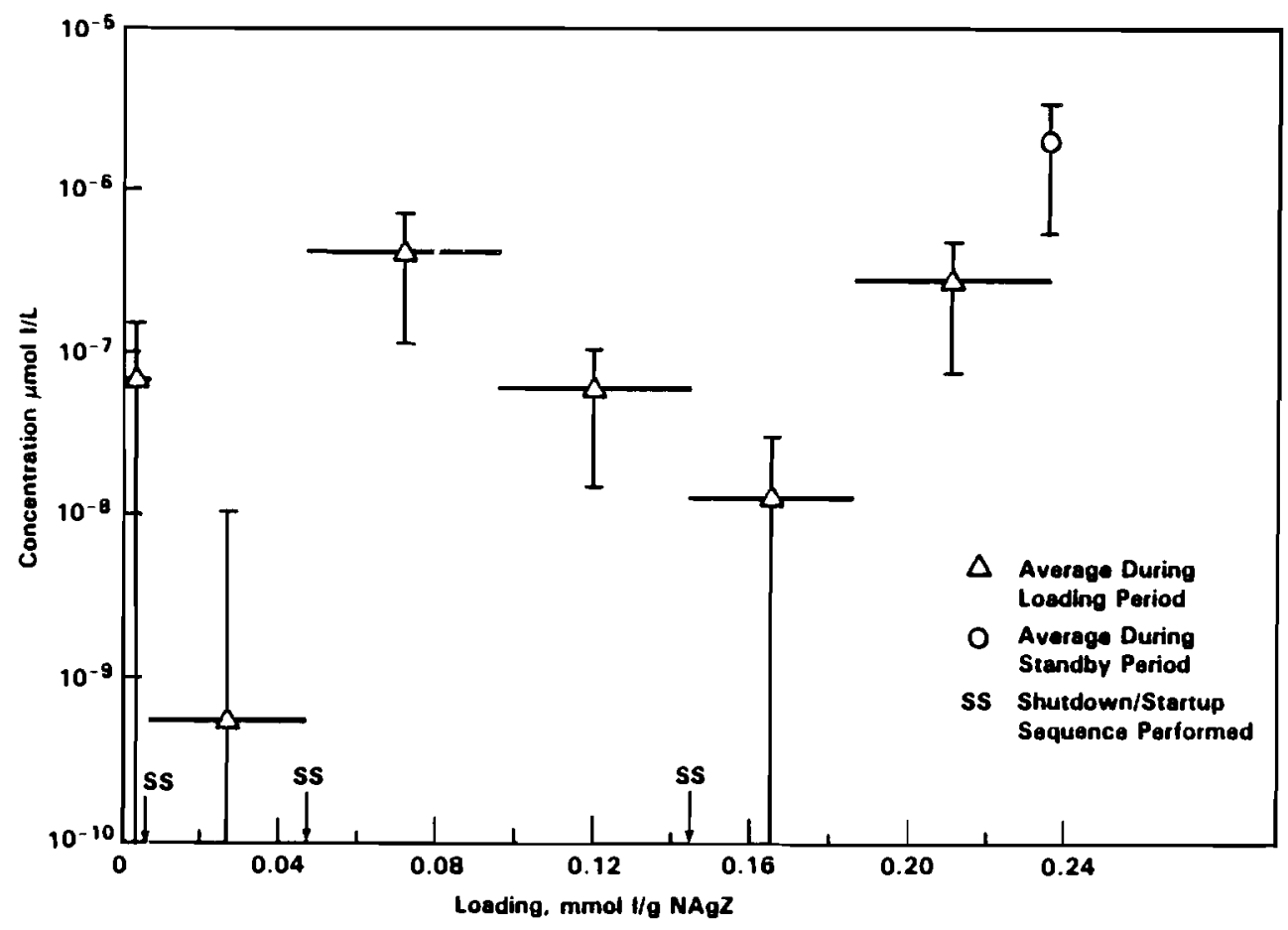

7A. Bed 1

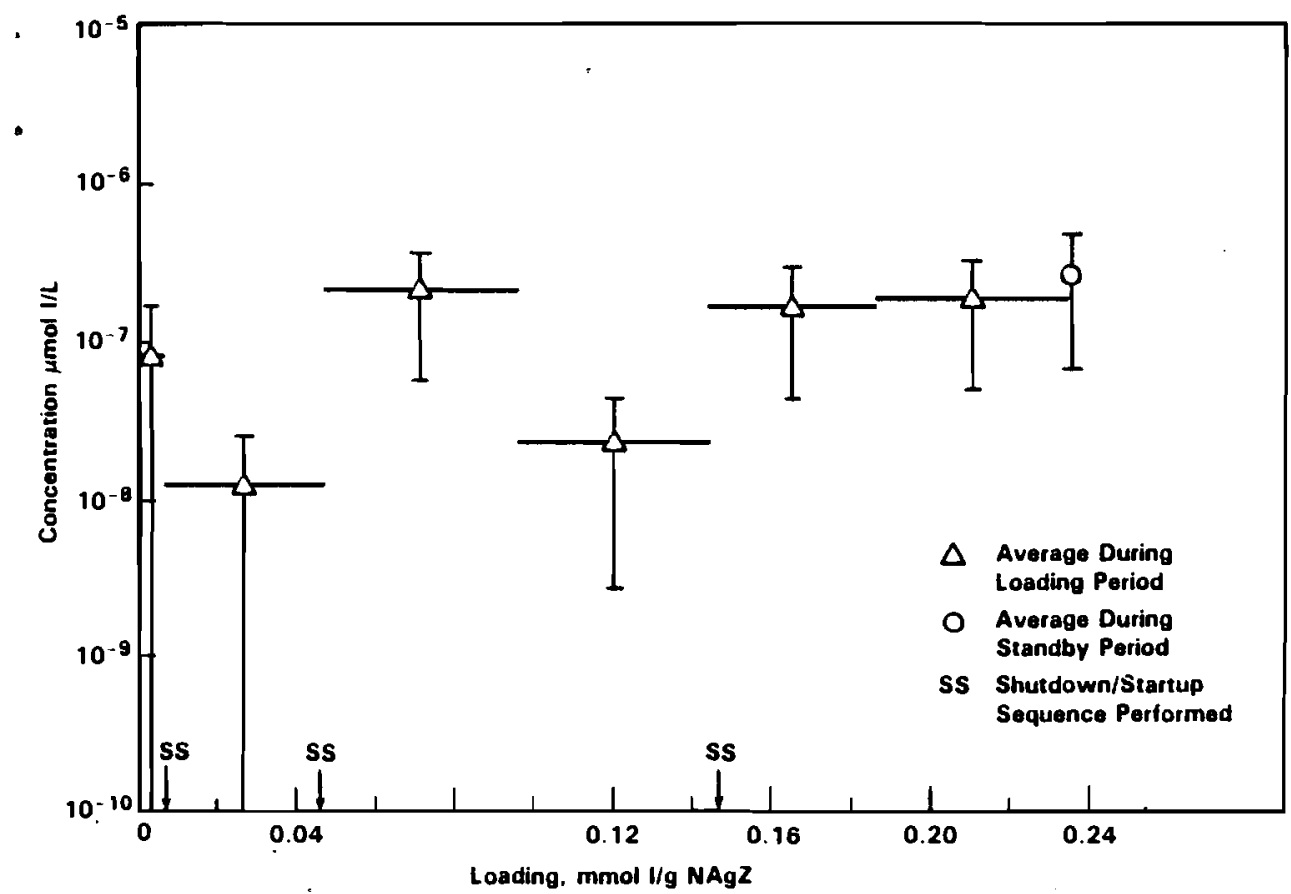

7B. Bed 4 .

FIGURE 7. Effluent Concentrations from NAgZ Beds as a Function of Iodine Loading. (Input Gas: $0.1 \mu \mathrm{mol} \mathrm{I} / \mathrm{L}, 1$ vol\% $\mathrm{NO}$, and 1 vol\% $\mathrm{NO}_{2}$ ) 


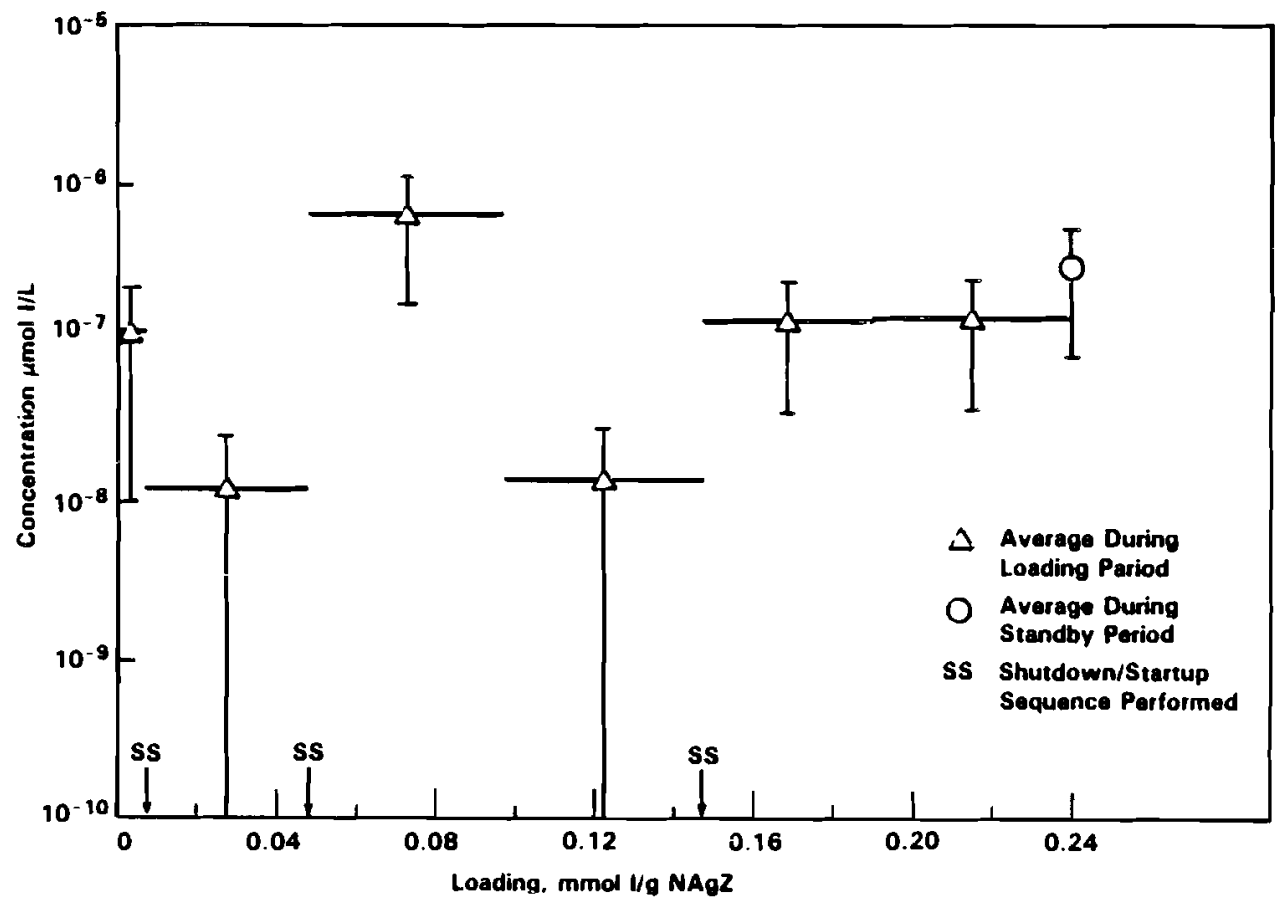

7C. Bed 7.

FIGURE 7. (contd)

Table 2 also shows that iodine collected on the first $10 \mathrm{~cm}$ for beds 1 and 7 and the first $13 \mathrm{~cm}$ for bed 4 , indicating that the mass transfer zone for NAgZ is probably less than $12 \mathrm{~cm}$.

In addition to the planned tests, bed 4 was accidently flooded with water before the first shutdown. The bed's performance was not significantly impacted by the flooding, although the small differences observed between bed 4 and beds 1 and 7 might be attributable to the flooding.

The different beds after loading and before standby were presented earlier in Figure 6 . Inspection of beds 1,4 , and 7 shows a dark band at the top of each bed. About $5 \mathrm{~mm}$ down each bed, a gap formed after the first shutdown/startup cycle. When the material was removed from the glass columns at the end of the experiments, the upper highly loaded portion of the bed was agitated. The material then flowed easily. This suggests that exposure to the simulated DOG of the PFM or occasional condensation during shutdown 


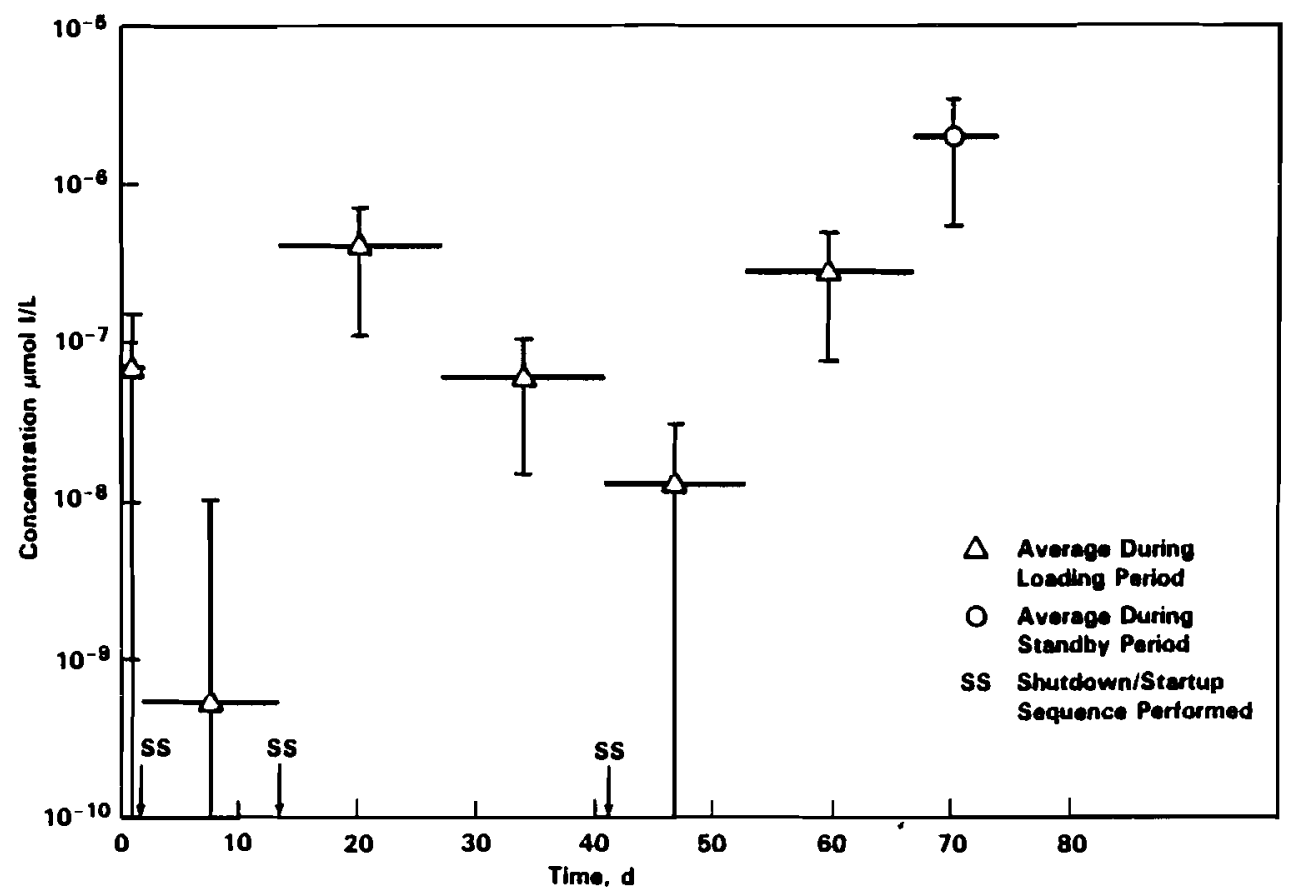

8 A. Bed 1

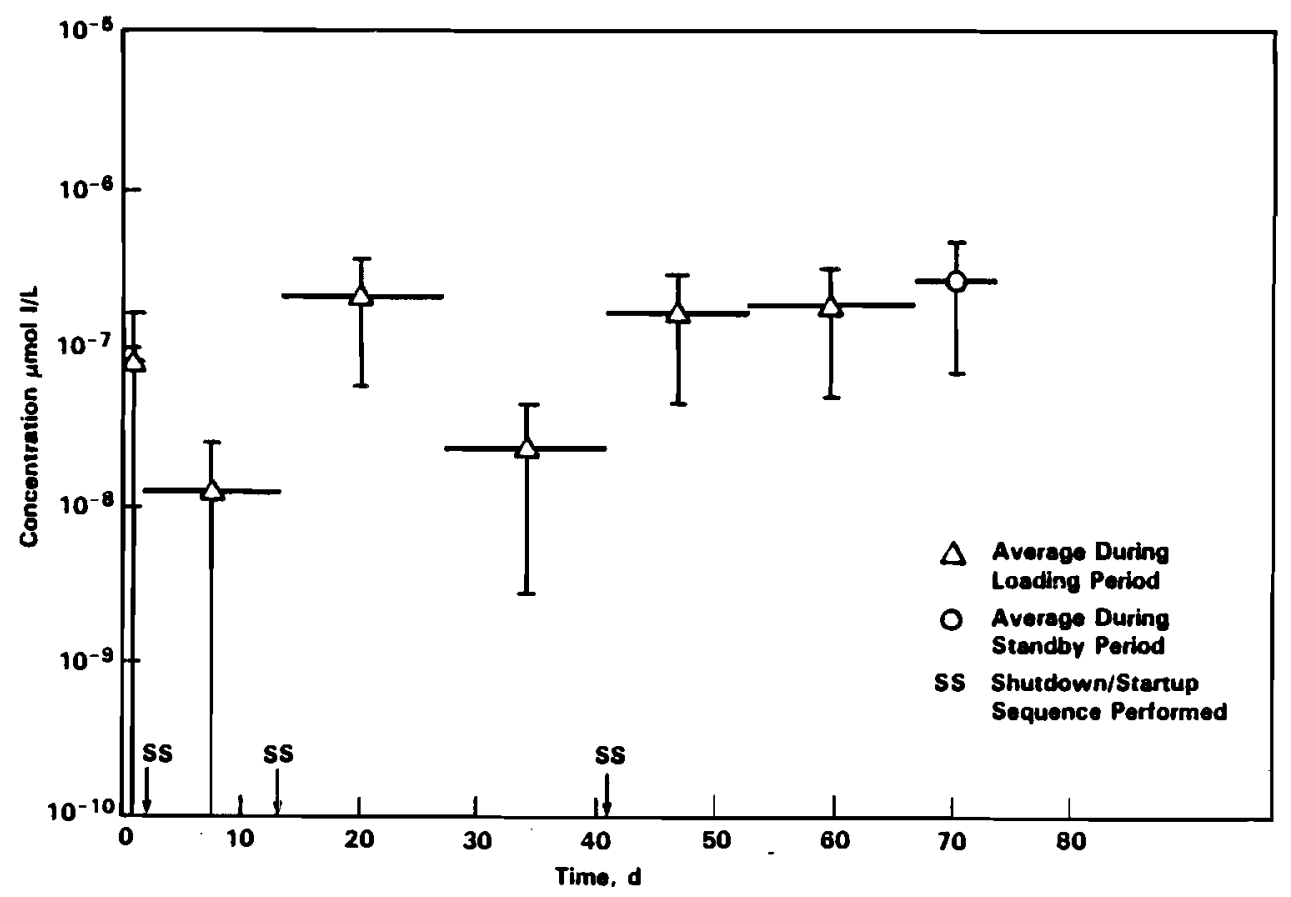

$8 B$, Bed 4

FIGURE 8. Effluent Concentrations from NAgZ Beds as a Function of Time. (Input Gas: $0.1 \mu \mathrm{mo}$ ! I/L, 1 vol\% NO, and 1 vol\% $\mathrm{NO}_{2}$ ) 


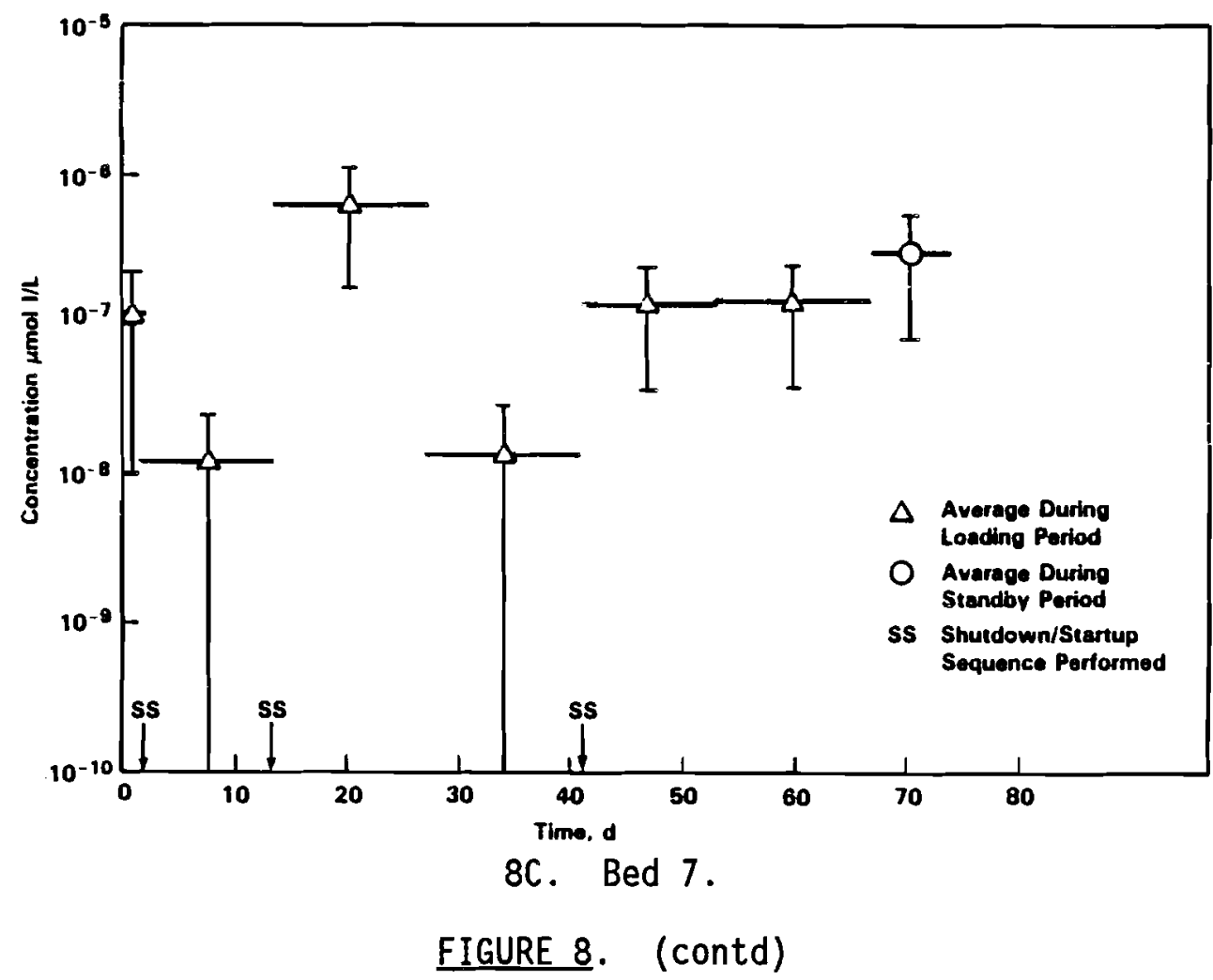

would cause some agglomeration of the material, which could result in blockage. Based on pressure drop measurements, which are discussed later, no significant blockage occurred.

At room temperature the NAgZ was dark gray. Upon heating to $150^{\circ} \mathrm{C}$, the material changed to a tannish gray-white. At the end of the experiment the top $1 \mathrm{~cm}$ of each bed was dark brown, the next $4 \mathrm{~cm}$ section was light yellow, the next $1 \mathrm{~cm}$ was pale violet, and the remainder of each bed was tannish gray-white. This configuration suggests a mass transfer zone of about $6 \mathrm{~cm}$. The apparent discrepancy in mass transfer zone probably results because the color method is less sensitive. The segmented gamma count provides a more accurate measure.

The results of the NAgZ tests show that NAgZ would be an effective trap= ping agent for gaseous iodine present in the DOG of the PFM, up to an iodine loading of $0.25 \mathrm{mmol} \mathrm{I} / \mathrm{g} \mathrm{NAgZ}$. The loading profile also indicates that higher loadings should be possible at PFM process conditions. 
IABLE 2. Iodine Distribution on NAgZ Beds Before and After Standby

Segment,

$3.3 \mathrm{~cm} /$ segment

\section{Bed 1}

$0-3.3 \mathrm{~cm}$

$3.3-6.6 \mathrm{~cm}$

$6.6-9.9 \mathrm{~cm}$

$9.9-13.2 \mathrm{~cm}$

$13.2-16.5 \mathrm{~cm}$

$16.5-20.0 \mathrm{~cm}$

TOTAL
0.083

0.079

0.073

0.0002

0.0001

$\underline{0.0001}$

0.2354

0.137

0.026

0.046

0.026

$9.9-13.2 \mathrm{~cm}$

$13.2-16.5 \mathrm{~cm}$

0.0001

$16.5-20.0 \mathrm{~cm}$

$\underline{0.0001}$

TOTAL

Bed 4

$-3.3 \mathrm{~cm}$

$3.3-6.6 \mathrm{~cm}$
Before Standby $\%$ (a)

Loading

$\frac{\text { After Standby }}{\text { mmol I/g AgZ }}$

$58.12 \pm 2.92$

0.138

$58.77 \pm 3.13$

$11.13 \pm 1.07$

0.026

$11.05 \pm 1.14$

$19.55 \pm 1.47$

0.039

$16.55 \pm 1.42$

$11.13 \pm 1.07$

0.031

$13.23 \pm 1.26$

$0.04 \pm 0.06$

0.0008

$0.33 \pm 0.19$

$\underline{0.03 \pm 0.05 \quad \underline{0.0001}}$

$\underline{0.06 \pm 0.08}$

Bed 7

\begin{tabular}{lllll}
$0-3.3 \mathrm{~cm}$ & 0.104 & $43.34 \pm 2.87$ & 0.101 & $42.15 \pm 2.78$ \\
$3.3-6.6 \mathrm{~cm}$ & 0.062 & $25.76 \pm 2.07$ & 0.053 & $22.09 \pm 1.87$ \\
$6.6-9.9 \mathrm{~cm}$ & 0.073 & $30.57 \pm 2.30$ & 0.073 & $30.47 \pm 2.26$ \\
$9.9-13.2 \mathrm{~cm}$ & 0.0006 & $0.23 \pm 0.17$ & 0.012 & $5.16 \pm 0.84$ \\
$13.2-16.5 \mathrm{~cm}$ & 0.0001 & $0.05 \pm 0.08$ & 0.0001 & $0.06 \pm 0.09$ \\
$16.5-20.0 \mathrm{~cm}$ & $\underline{0.0001}$ & $\underline{0.05 \pm 0.08}$ & $\underline{0.0001}$ & $\underline{0.06 \pm 0.08}$ \\
\cline { 3 - 3 } & 0.2398 & 100.00 & 0.2398 & 99.99
\end{tabular}

(a) $95 \%$ confidence level based on counting statistics. 


\section{Linde Silver Mordenite}

As shown in Figures 9 and 10, LAgZ can reduce the iodine concentration in the gas stream from $0.1 \mu \mathrm{mol} \mathrm{I} / \mathrm{L}$ to less than the target concentration of $10^{-5} \mu \mathrm{mol} \mathrm{I} / \mathrm{L}$, up to an iodine loading of $0.27 \mathrm{mmol} \mathrm{I} / \mathrm{g} \mathrm{LAgZ}$. During loading the effluent concentration from the bed was routinely $\left.<10^{-5} \mu \mathrm{mo}\right] \mathrm{I} / \mathrm{L}$. Standby and the shutdown/startup cycles apparently had little effect on the ability of LAgZ to trap gaseous iodine from a simulated DOG. The effluent sampler trap following the third shutdown/startup cycle could not be analyzed because it was accidently combined with the effluent sample trap from bed 8 $\left(\mathrm{AgNO}_{3} \mathrm{Si}\right)$, which was very radioactive. We could not separate the two samples and be sure that the integrity of the sample from bed 9 was maintained.

Table 3 indicates that iodine collected in the top $7 \mathrm{~cm}$ of the bed, compared to the top $11 \mathrm{~cm}$ of the beds of NAgZ. This suggests a mass transfer zone of $<7 \mathrm{~cm}$ for LAgZ at PFM process conditions. The loading distribution also indicates that a $20 \mathrm{~cm}$ bed of LAgZ couid be loaded to a much higher loading than the $0.27 \mathrm{mmol} \mathrm{I} / \mathrm{g}$ LAgZ that was achieved in this experiment.

Standby for 7 days appears to have caused some of the iodine trapped in the first $3 \mathrm{~cm}$ of the bed to migrate into the next $3 \mathrm{~cm}$. None of the iodine appears to have migrated below the origirial loading zone. Based on a single bed of LAgZ it is difficult to assess any differences between LAgZ and NAgZ during standby. Comparison of Tables 2 and 3 shows iodine migration during standby for NAgZ from the second $3 \mathrm{~cm}$ to the lower regions, while for LAgZ no material moved into the previously loaded LAgZ.

Following the second shutdown/startup cycle, a smal1 crack or gap formed immediately below the loading zone at about $5 \mathrm{~mm}$, similar to the gap observed in the NAgZ beds. As with the NAgZ, agitation was required before the material could be removed from the glass column. After breaking the crusty upper layer, the material flowed easily from the columin. A longer test time would be required to determine whether significant degradation of the LAgZ will occur, which could impact the use of LAgZ in the PFM.

The as-received LAgZ was white instead of dark gray like the NAgZ. Upon heating to $150^{\circ} \mathrm{C}$, the LAgZ remained white. As iodine loaded onto the material it became red violet; however, with time the top 1 to $2 \mathrm{~mm}$ of the bed 


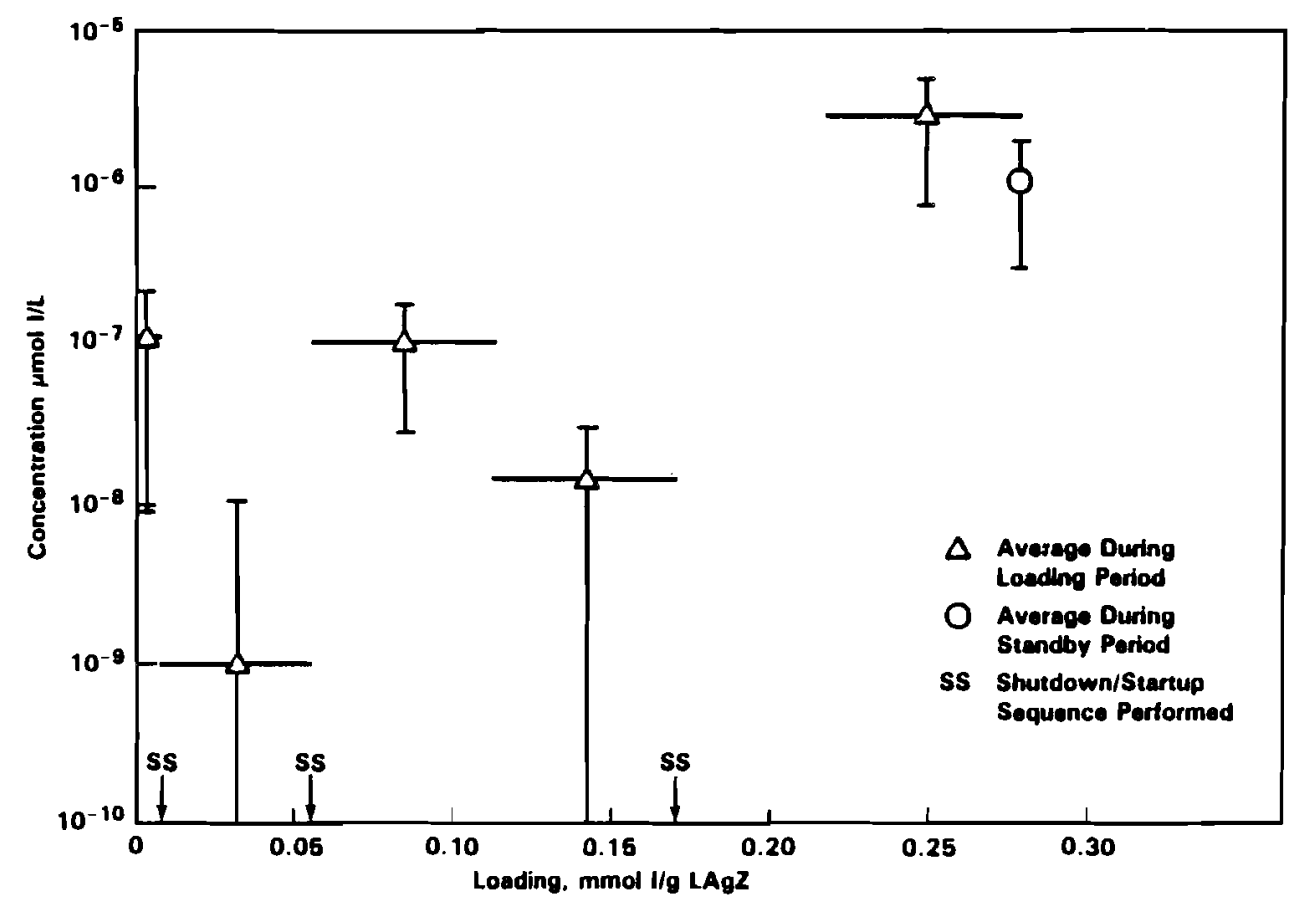

FIGURE 9. Effluent Concentrations from LAgZ Bed 9 as a Function of Iodine Loading. (Input Gas: $0.1 \mu \mathrm{mol} \mathrm{I} / \mathrm{L}, 1$ vol\% $\mathrm{NO}$, and 1 vol\% $\mathrm{NO}_{2}$ )

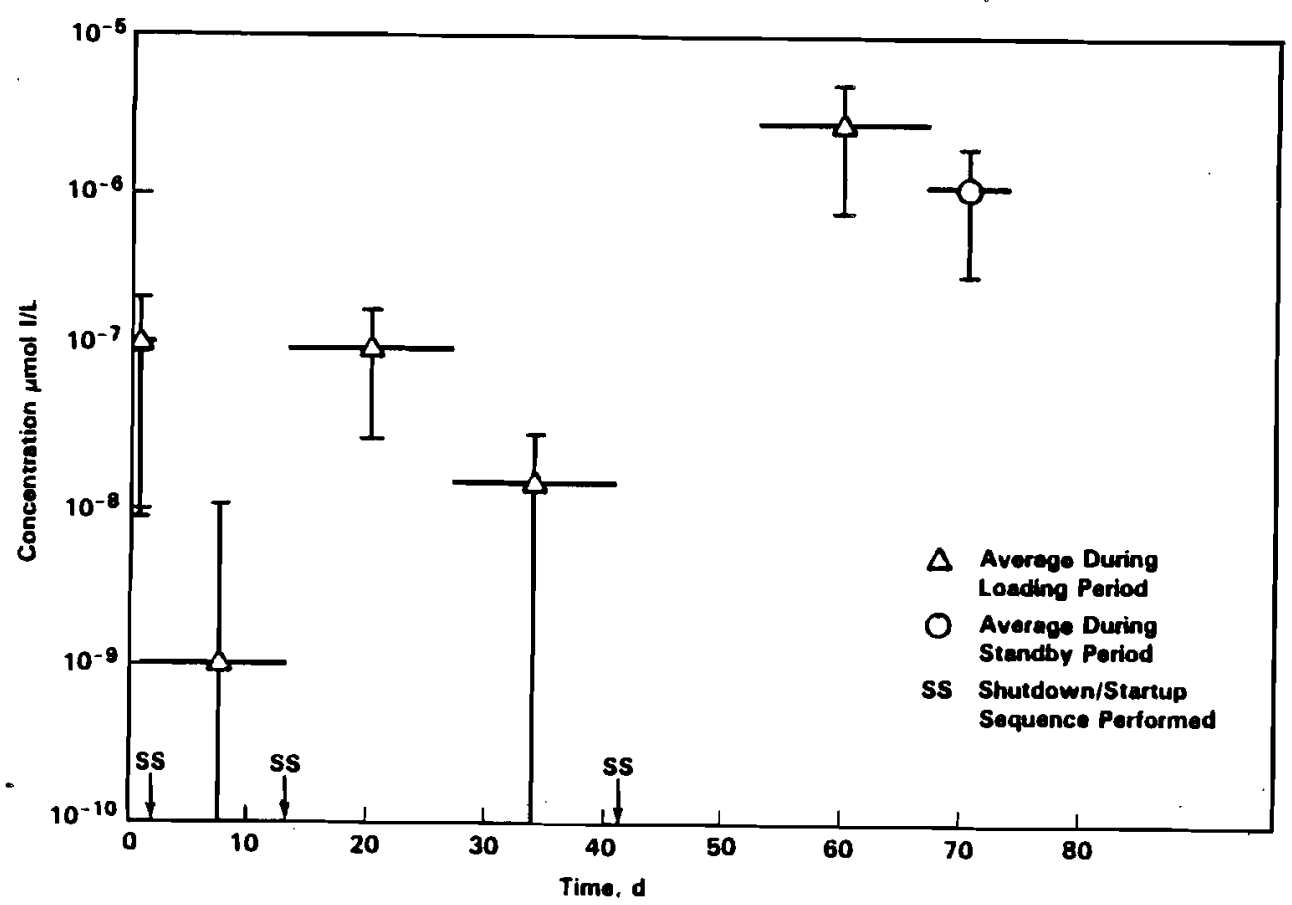

FIGURE 10. Effluent Concentration from LAgZ Bed 9 as a Function of Time. (Input Gas: $0.1 \mu \mathrm{mol} I / L, 1$ vol\% $\mathrm{NO}$, and 1 vol\% $\mathrm{NO}_{2}$ ) 
TABLE 3. Iodine Distribution on LAgZ Bed Before and After Standby

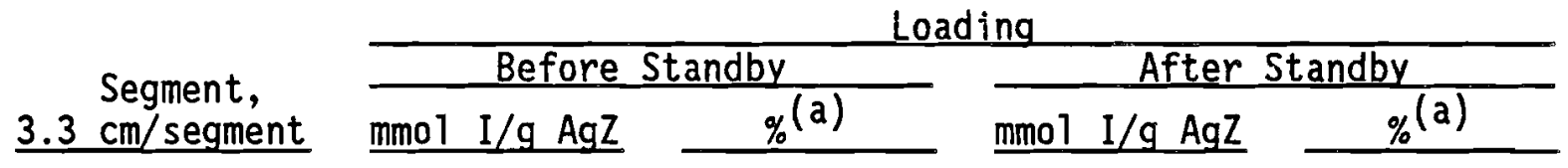
Bed 9

\begin{tabular}{llrlr}
$0-3.3 \mathrm{~cm}$ & 0.221 & $79.38 \pm 3.43$ & 0.203 & $72.98 \pm 3.47$ \\
$3.3-6.6 \mathrm{~cm}$ & 0.057 & $20.50 \pm 1.43$ & 0.075 & $26.83 \pm 1.80$ \\
$6.6-9.9 \mathrm{~cm}$ & 0.0001 & $0.04 \pm 0.05$ & 0.0001 & $0.05 \pm 0.07$ \\
$9.9-13.2 \mathrm{~cm}$ & 0.0001 & $0.03 \pm 0.05$ & 0.0001 & $0.05 \pm 0.07$ \\
$13.2-16.5 \mathrm{~cm}$ & 0.0001 & $0.03 \pm 0.05$ & 0.0001 & $0.05 \pm 0.07$ \\
$16.5-20.0 \mathrm{~cm}$ & $\underline{0.0001}$ & $\underline{0.03 \pm 0.05}$ & $\underline{0.0001}$ & $\underline{0.05 \pm 0.07}$ \\
\cline { 3 - 4 } & & & & \\
TOTAL & 0.2783 & 100.01 & 0.2783 & 100.01
\end{tabular}

(a) $95 \%$ confidence level based on counting statistics.

became white. At the end of the experiment the top 1 to $2 \mathrm{~mm}$ was white with some dark particles intermixed, and the next $1 \mathrm{~cm}$ was a dark pinkish-purple band followed by an uneven pale pink band about $1 \mathrm{~cm}$ deep. The rest of the bed was white. This configuration indicates a mass transfer zone of 2 to $3 \mathrm{~cm}$. Again, the difference in observed mass transfer zones between that measured by segmented gamma count and by color likely results because the color method is less analytically sensitive.

This experiment indicates that LAgZ would be an effective sorbent for gaseous iodine present in the DOG of the PFM. The material can routinely reduce the iodine concentration in the gas stream to less than the target concentration of $10^{-5} \mu \mathrm{mol} \mathrm{I} / \mathrm{L}$. Based on this experiment, this material may be a suitable substitute for NAgZ.

\section{Linde Silver Faujasite}

As shown in Figures 11 and $12,18 \mathrm{wt} \% \mathrm{AgX}$ was an effective trapping agent for gaseous iodine in the simulated PFM DOG. The AgX can routinely reduce the iodine concentration in the gas stream from $0.1 \mu \mathrm{mol} \mathrm{I} / \mathrm{L}$ to less 


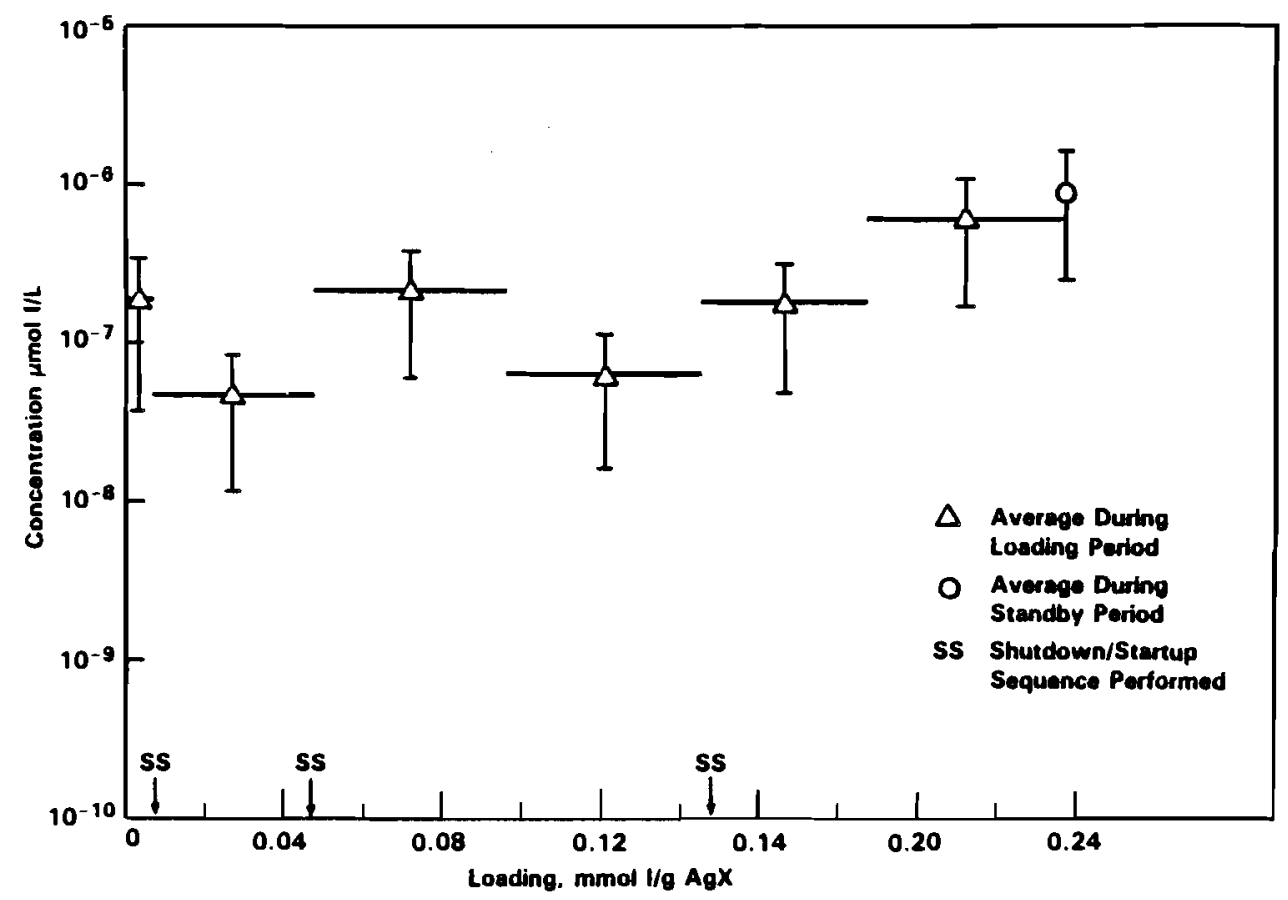

11A. Bed 3 .

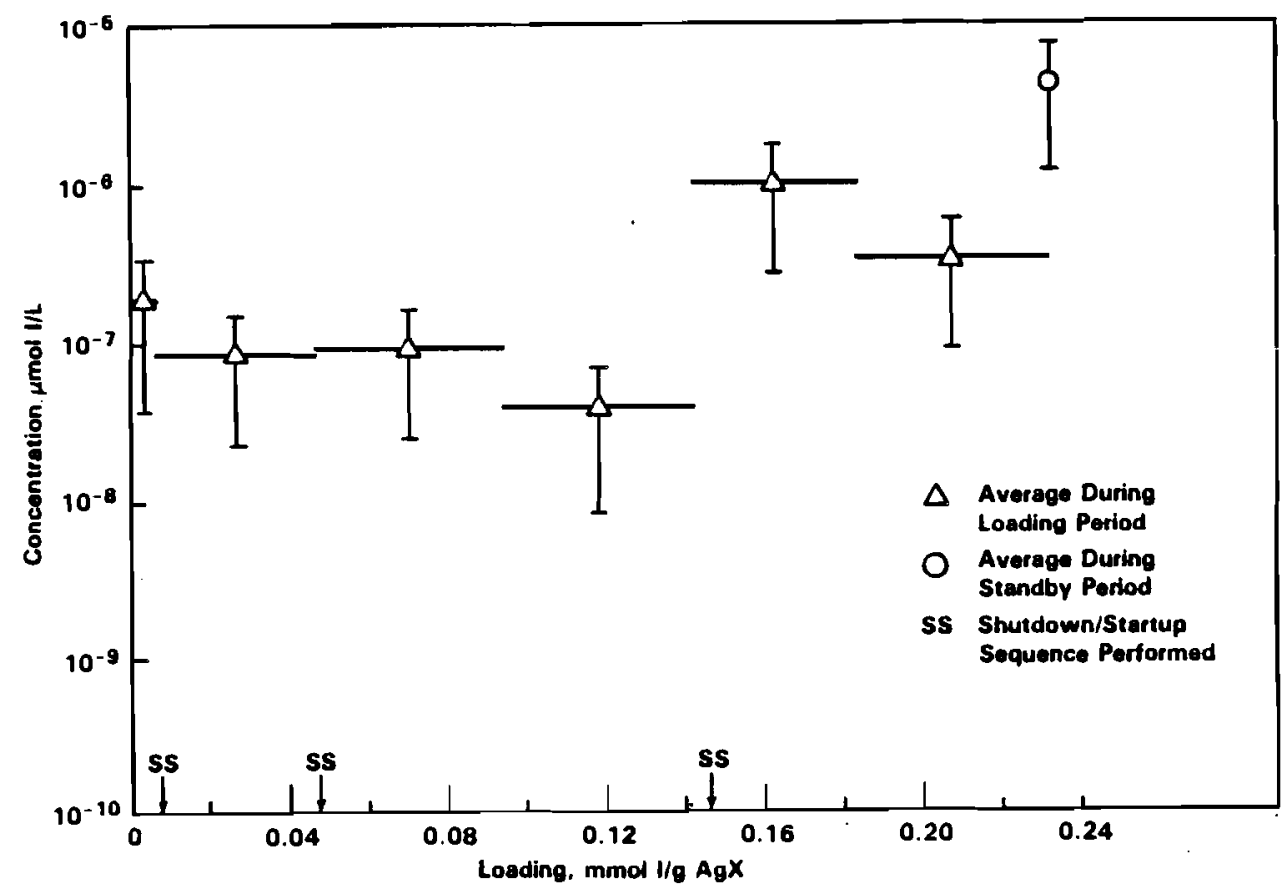

11B. Bed 6.

FIGURE 11. Effluent Concentrations from $18 \mathrm{wt} \% \mathrm{Ag} \mathrm{AgX} \mathrm{Beds} \mathrm{as} \mathrm{a}$ Function of Iodine Loading. (Input Gas: $1 \mu \mathrm{mol} \mathrm{I} / \mathrm{L}$, 1 vol\% $\mathrm{NO}$, and 1 vol\% $\mathrm{NO}_{2}$. ) 


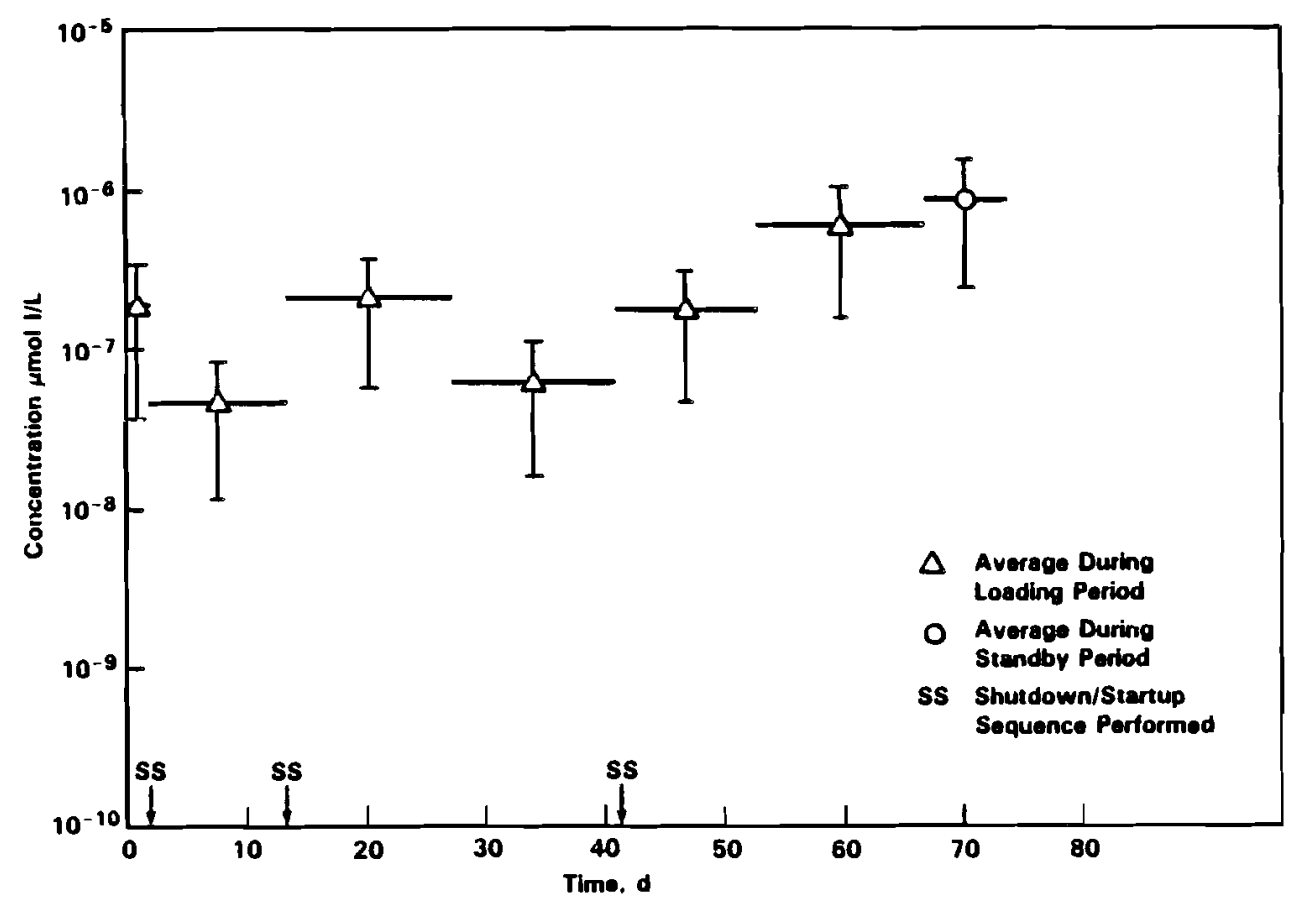

12A. Bed 3.

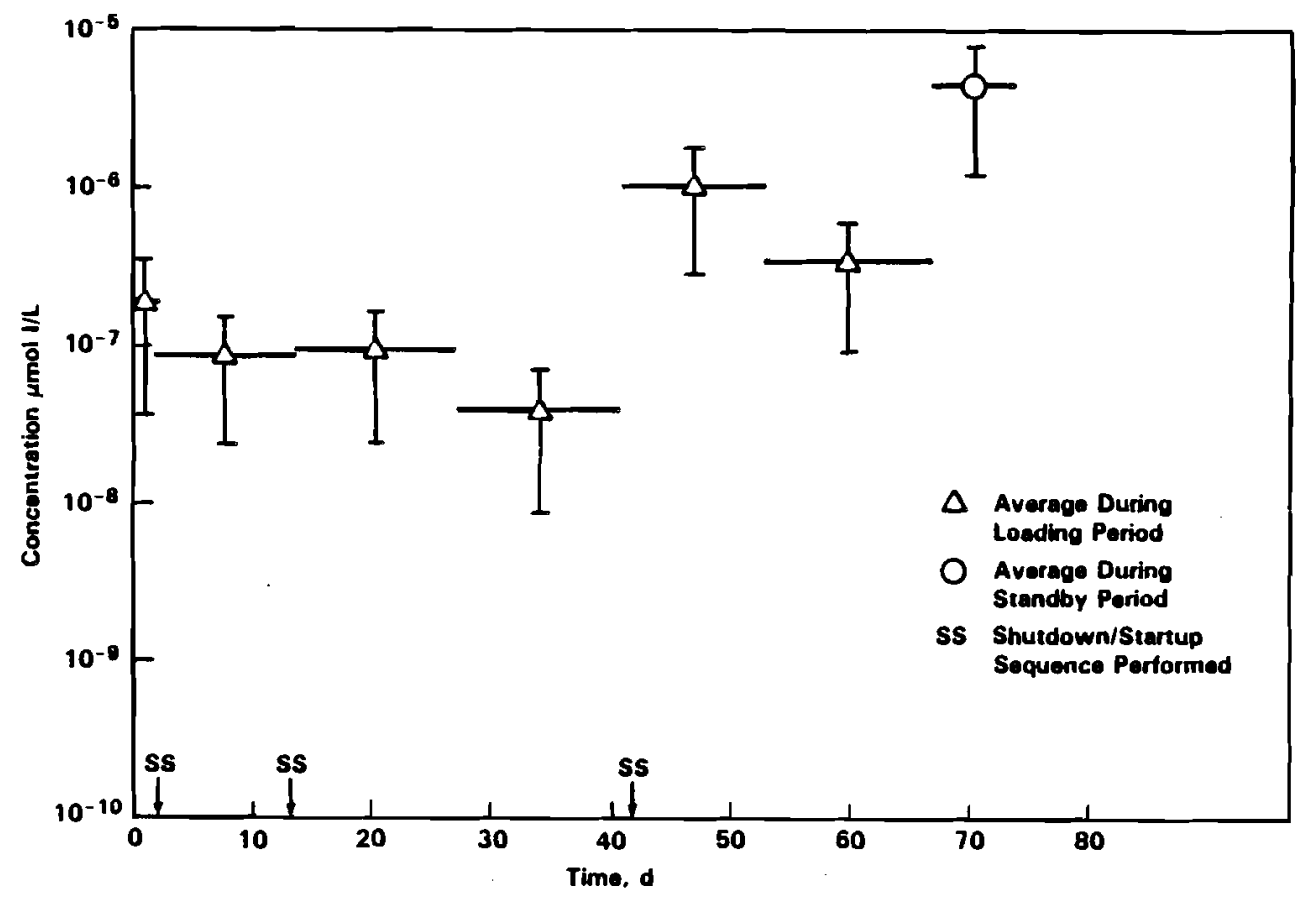

12B. Bed 6.

FIGURE 12. Effluent Concentrations from 18 wt\% Ag AgX as a Function of Time. (Input Gas: $1 \mu \mathrm{mol} \mathrm{I} / \mathrm{L}$, 1 vol\% $\mathrm{NO}$, and 1 vol\% $\mathrm{NO}_{2}$.) 
than the target concentration of $10^{-5} \mu \mathrm{mol} \mathrm{I} / \mathrm{L}$, up to an iodine loading of $0.24 \mathrm{mmol} \mathrm{I} / \mathrm{g} \mathrm{LAgZ}$. The AgX routinely reduced the concentration to $<10^{-6} \mu \mathrm{mol} \mathrm{I} / \mathrm{L}$ during loading, independent of whether the material was exposed to a shutdown/startup cycle. The chronic release during standby was al so less than $10^{-6} \mu \mathrm{mol} \mathrm{I} / \mathrm{L}$.

The loading profile measured for the AgX, as shown in Table 4, indicates that the iodine collected in the top 3 or $6 \mathrm{~cm}$ of the bed. Subsequent exposure to standby conditions for 7 days caused no significant redistribution or loss of the iodine. Comparison of the iodine distribution of the AgX and the NAgZ beds shows a sharper loading band for the AgX. Essentially all of the trapped iodine was located in the first $3.3 \mathrm{~cm}$ of the bed. This suggests a mass transfer zone of less than $4 \mathrm{~cm}$, while iodine was found in the first $10 \mathrm{~cm}$ of the NAgZ beds. This loading pattern suggests that a higher silver utilization might be possible with the AgX than with NAgZ or LAgZ, and that a much higher loading than $0.24 \mathrm{mmol} \mathrm{I} / \mathrm{g} \mathrm{AgX}$ could be achieved.

Following the second shutdown/startup cycle, small voids formed at the leading edge of the iodine loading band, $5 \mathrm{~mm}$ into the bed. As the experiment progressed the void expanded to $1 \mathrm{~mm}$ wide. As with the mordenites, to remove the AgX from the glass columns the upper $5 \mathrm{~mm}$ layer had to be agitated, after which the material flowed easily from the glass column. A longer test time would be required to determine if this agglomeration would significantly impact the use of AgX in the PFM.

The as-received AgX was 1 ight tan at both room temperature and $150^{\circ} \mathrm{C}$. As the iodine loaded onto the AgX, the material became yellow. The loading zone became dark brown as more iodine was trapped. Eventually, the $5 \mathrm{~mm}$ of AgX above the void became white. The next $1 \mathrm{~cm}$ below the crack became light violet, eventually turning into a pinkish-brown band about $1 \mathrm{~cm}$ wide. This configuration suggests that the mass transfer zone was less than $2 \mathrm{~cm}$.

These experiments indicate that $18 \mathrm{wt} \% \mathrm{Ag} \mathrm{AgX}$ would be an effective sorbent for gaseous iodine present in the DOG of the PFM. The material can routinely reduce the iodine concentration in a simulated DOG to less than the 
TABLE 4. Iodine Distribution on AgX Beds Before and After Standby

\begin{tabular}{|c|c|c|c|c|}
\hline & & & ing & \\
\hline & Before & & After & \\
\hline $3.3 \mathrm{~cm} /$ segment & $\mathrm{mmol} \mathrm{I} / \mathrm{g} \mathrm{AgZ}$ & $\%(a)$ & $\mathrm{mmol} \quad \mathrm{I} / \mathrm{g} \mathrm{AgZ}$ & $\%(a)$ \\
\hline
\end{tabular}
Bed 3

$\begin{array}{llrlr}0-3.3 \mathrm{~cm} & 0.226 & 95.56 \pm 4.80 & 0.234 & 98.98 \pm 5.44 \\ 3.3-6.6 \mathrm{~cm} & 0.010 & 4.25 \pm 0.73 & 0.002 & 0.72 \pm 0.33 \\ 6.6-9.9 \mathrm{~cm} & 0.0001 & 0.05 \pm 0.08 & 0.0002 & 0.09 \pm 0.11 \\ 9.9-13.2 \mathrm{~cm} & 0.0001 & 0.05 \pm 0.08 & 0.0002 & 0.08 \pm 0.11 \\ 13.2-16.5 \mathrm{~cm} & 0.0001 & 0.05 \pm 0.08 & 0.0002 & 0.08 \pm 0.11 \\ 16.5-20.0 \mathrm{~cm} & \underline{0.0001} & \underline{0.04 \pm 0.07} & \underline{0.0002} & \underline{0.08 \pm 0.11} \\ & & & & \end{array}$

Bed 6

$\begin{array}{llrlr}0-3.3 \mathrm{~cm} & 0.230 & 99.52 \pm 5.20 & 0.230 & 99.43 \pm 5.30 \\ 3.3-6.6 \mathrm{~cm} & 0.0006 & 0.28 \pm 0.19 & 0.0006 & 0.28 \pm 0.20 \\ 6.6-9.9 \mathrm{~cm} & 0.0001 & 0.05 \pm 0.08 & 0.0002 & 0.07 \pm 0.10 \\ 9.9-13.2 \mathrm{~cm} & 0.0001 & 0.05 \pm 0.08 & 0.0002 & 0.07 \pm 0.10 \\ 13.2-16.5 \mathrm{~cm} & 0.0001 & 0.05 \pm 0.08 & 0.0002 & 0.07 \pm 0.10 \\ 16.5-20.0 \mathrm{~cm} & \underline{0.0001} & \underline{0.05 \pm 0.08} & \underline{0.0002} & \underline{0.07} \pm 0.10\end{array}$

$\begin{array}{lllll}\text { TOTAL } & 0.2316 & 100.00 & 0.2316 & 99.99\end{array}$

(a) $95 \%$ confidence level based on counting statistics

target concentration of $10^{-5} \mu \mathrm{mol} \mathrm{I} / \mathrm{L}$. Based on these experiments, $18 \mathrm{wt} \% \mathrm{Ag}$ AgX could be a suitable substitute for NAgZ. The results also imply that 36 wt\% Ag AgX merits further evaluation.

\section{$\mathrm{AgNO}_{3} \mathrm{Si}$}

As shown in Figures 13 and 14 , the silver nitrate-loaded silicic acid, $\mathrm{AgNO}_{3} \mathrm{Si}$, did not routinely reduce the concentration in the simulated DOG 


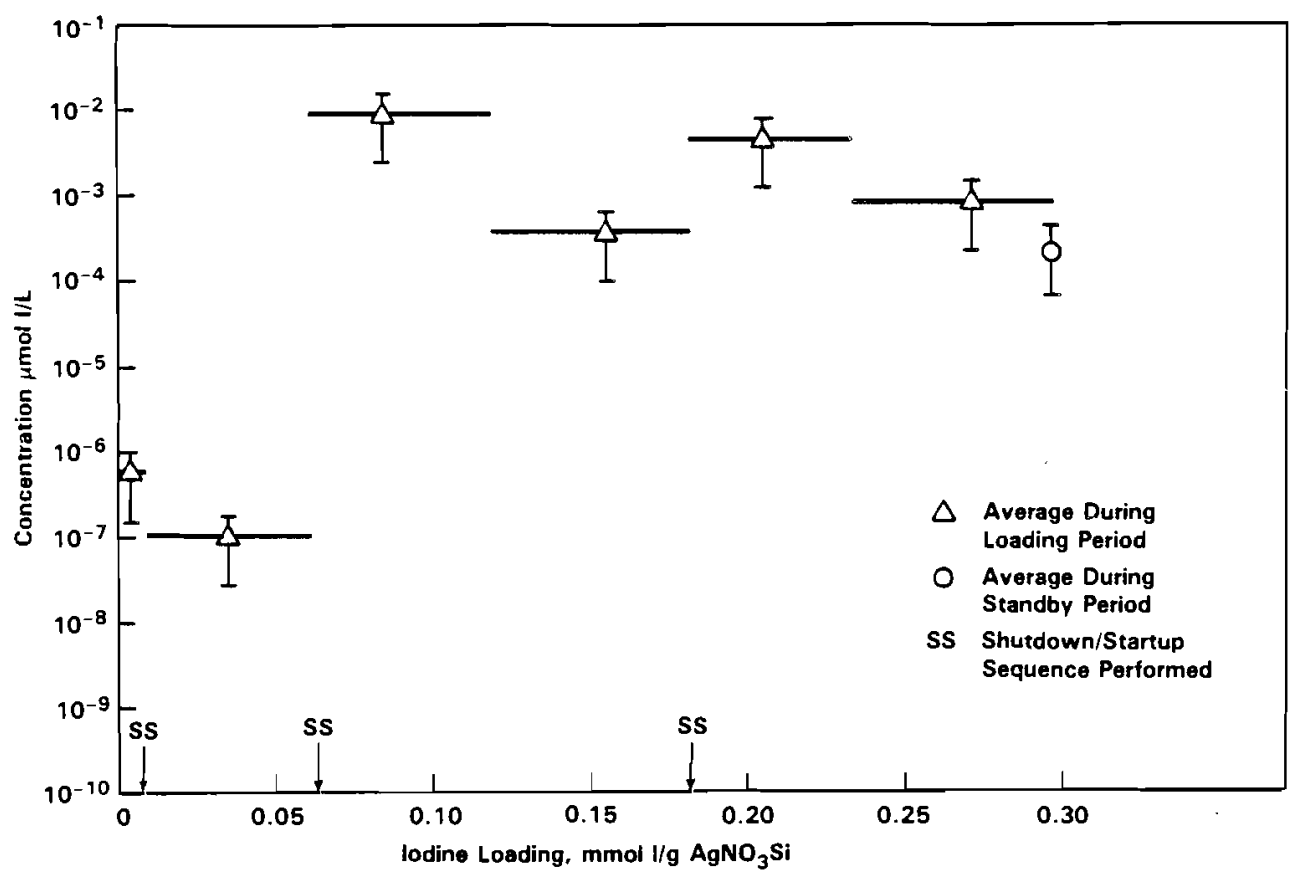

13A. Bed 2.

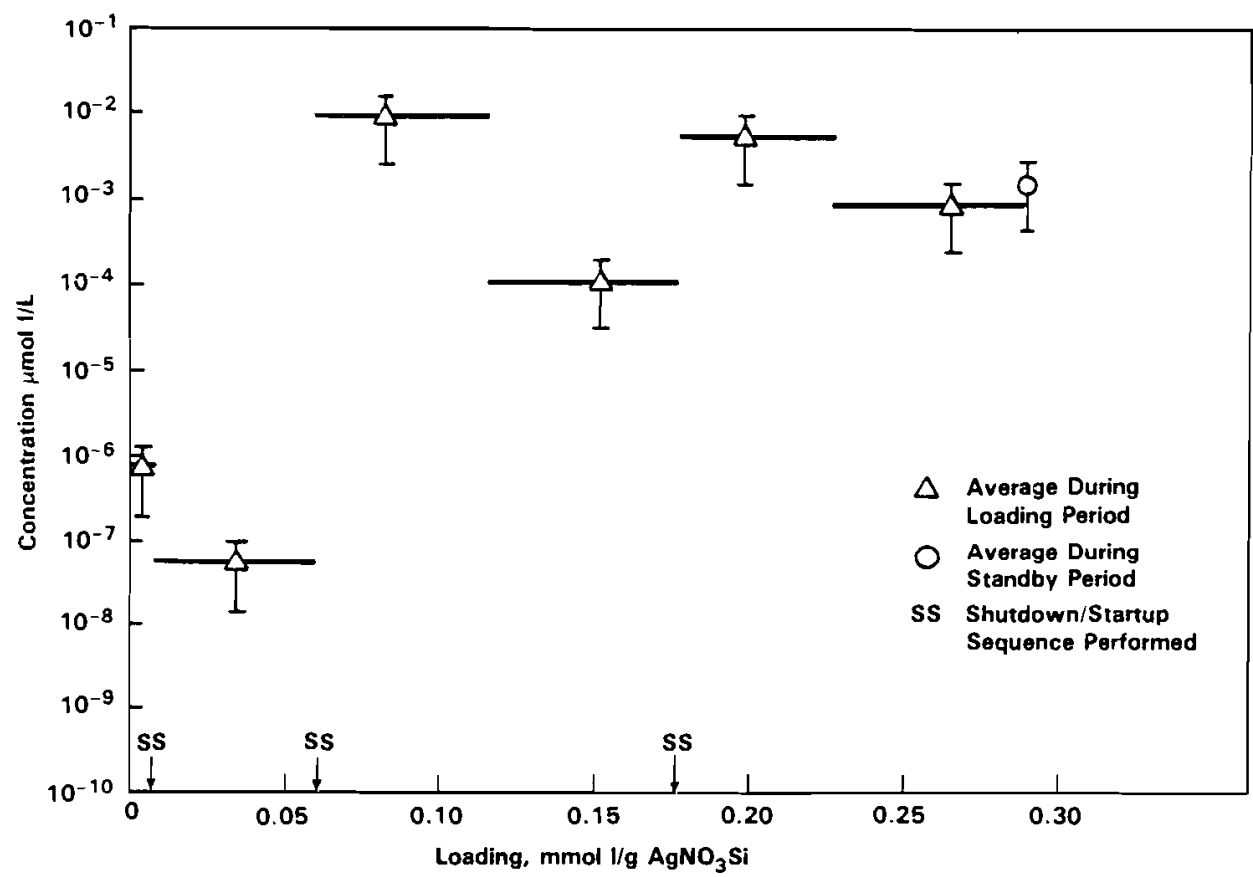

13B. Bed 5.

FIGURE 13. Effluent Concentrations from $\mathrm{AgNO}_{3} \mathrm{Si}$ Beds as a Function of Loading. (Input Gas: $1 \mu \mathrm{mol} \mathrm{I} / \mathrm{L}, 1$ vol\% $\mathrm{NO}$, and 1 vol\% $\mathrm{NO}_{2}$ ) 


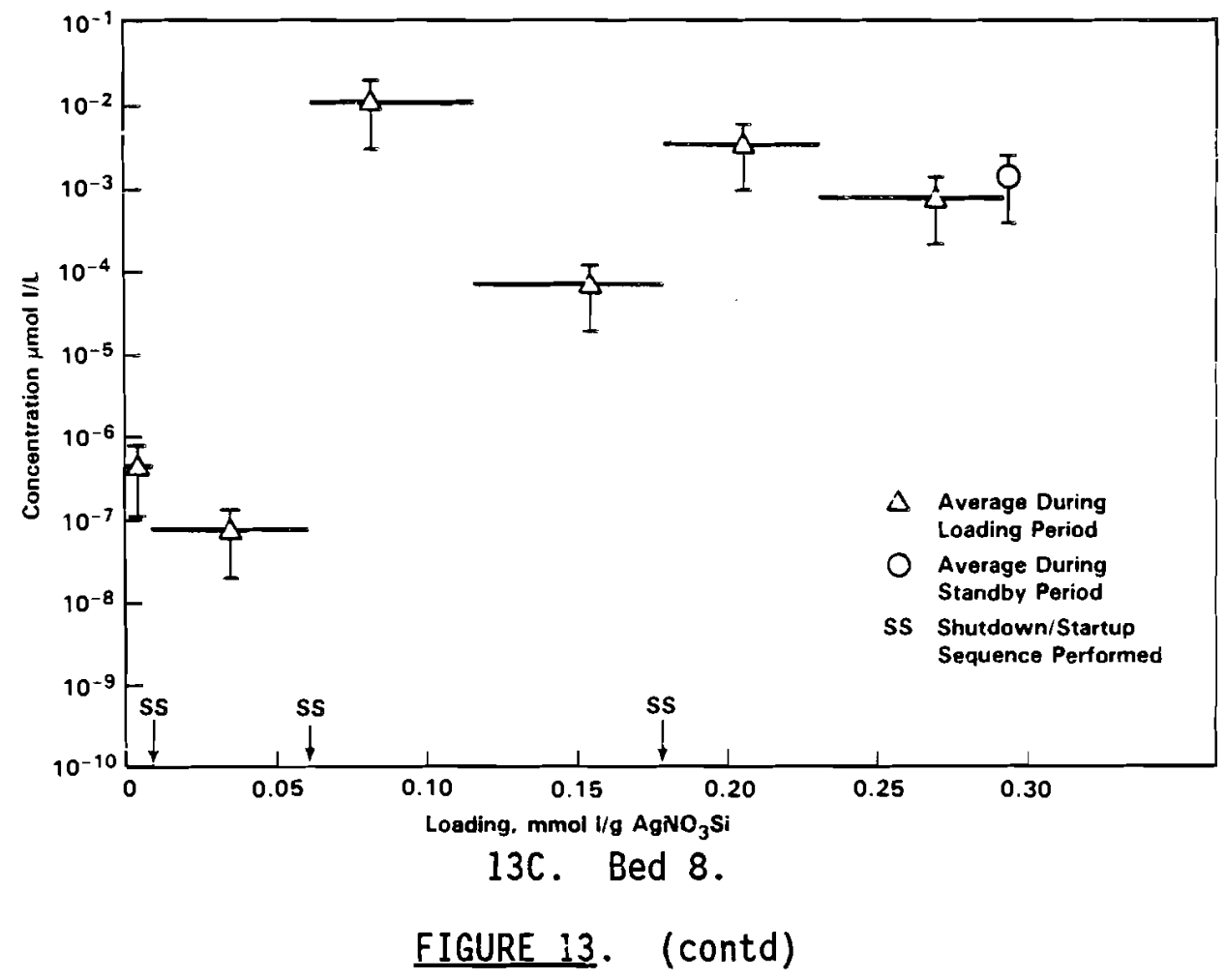

from $0.1 \mu \mathrm{mol} \mathrm{I} / \mathrm{L}$ to less than the target concentration of $10^{-5} \mu \mathrm{mol} \mathrm{I} / \mathrm{L}$. After the second shutdown/startup cycle, the effluent iodine concentration from all three beds increased to about $10^{-2} \mu \mathrm{mol} \mathrm{I} / \mathrm{L}$ and remained between $10^{-4}$ and $10^{-2} \mu \mathrm{mol} \mathrm{I} / \mathrm{L}$. Standby apparently has no effect on the effluent concentration from the beds. Whether shutdown/startup cycles affect the effluent concentration is unclear.

The effluent concentration during standby remained in the range observed during loading; thus, standby appears to have little or no adverse effect on the retention of iodine by the $\mathrm{AgNO}_{3} \mathrm{Si}$. Table 5 shows little change in distribution of iodine on the $\mathrm{AgNO}_{3} \mathrm{Si}$ beds. Table 5 also shows that the iodine is distributed throughout the $\mathrm{AgNO}_{3} \mathrm{Si}$ beds, which is not surprising considering the high effluent concentrations that were measured.

Contradictory evidence exists regarding the effect of shutdown/startup cycles on material performance. There was no loss in trapping ability after the first shutdown/startup cycle; however, following the second shutdown/ 


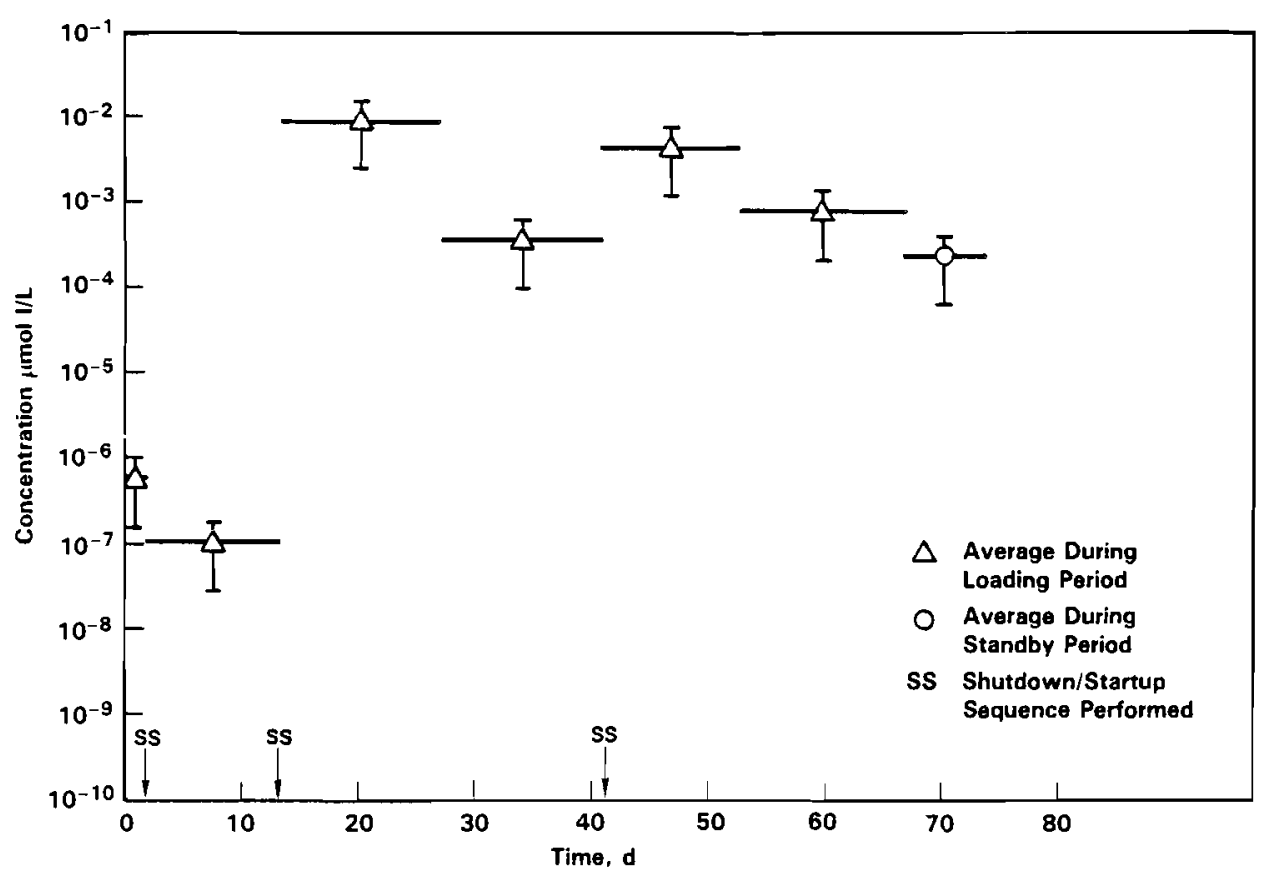

14A. Bed 2.

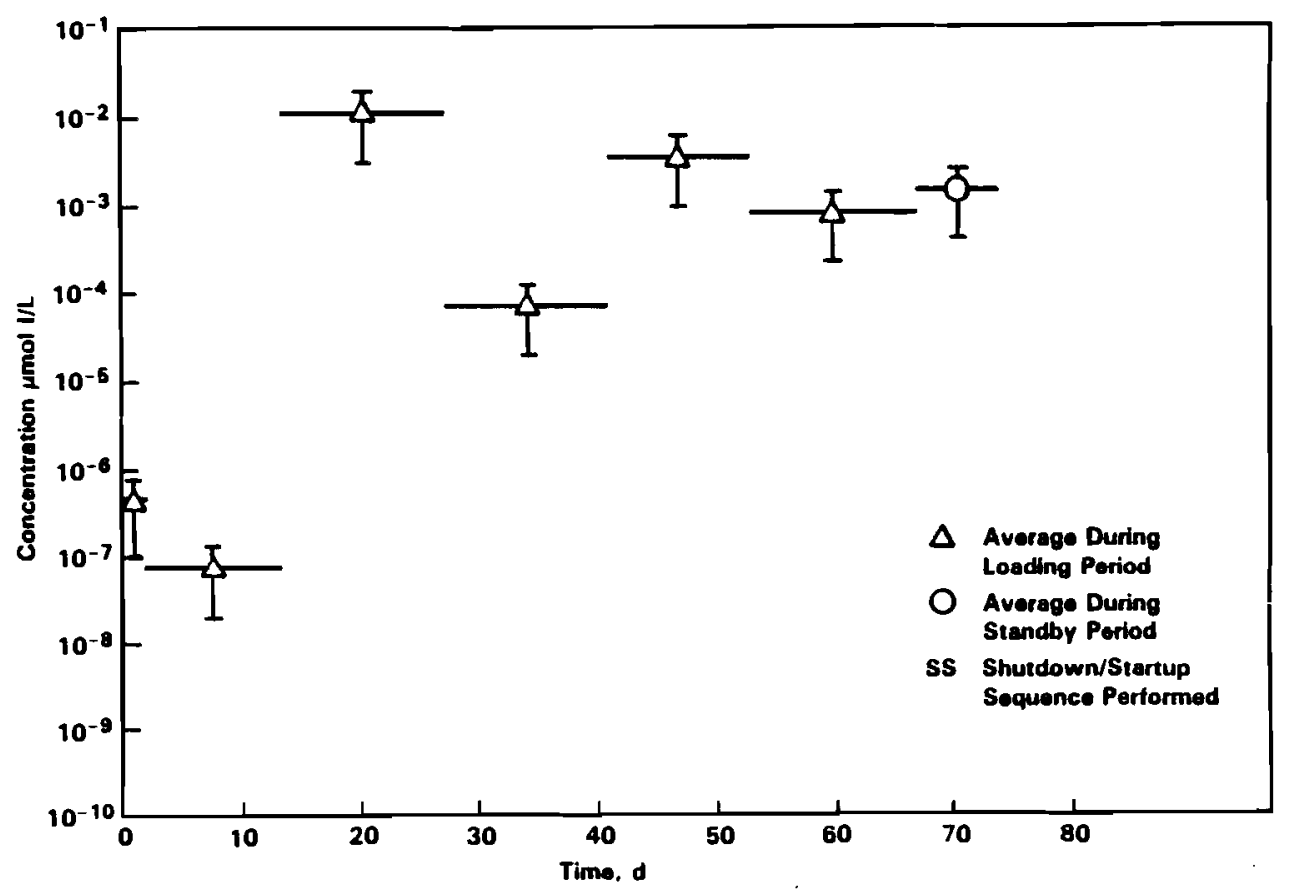

14B. Bed 5

FIGURE 14. Effluent Concentrations from $\mathrm{AgNO}_{3} \mathrm{Si}$ Beds as a Function of Time. (Input Gas: $1 \mu \mathrm{mol} \mathrm{I} / \mathrm{L}, 1$ vol\% $\mathrm{NO}$, and 1 vol\% $\mathrm{NO}_{2}$.) 


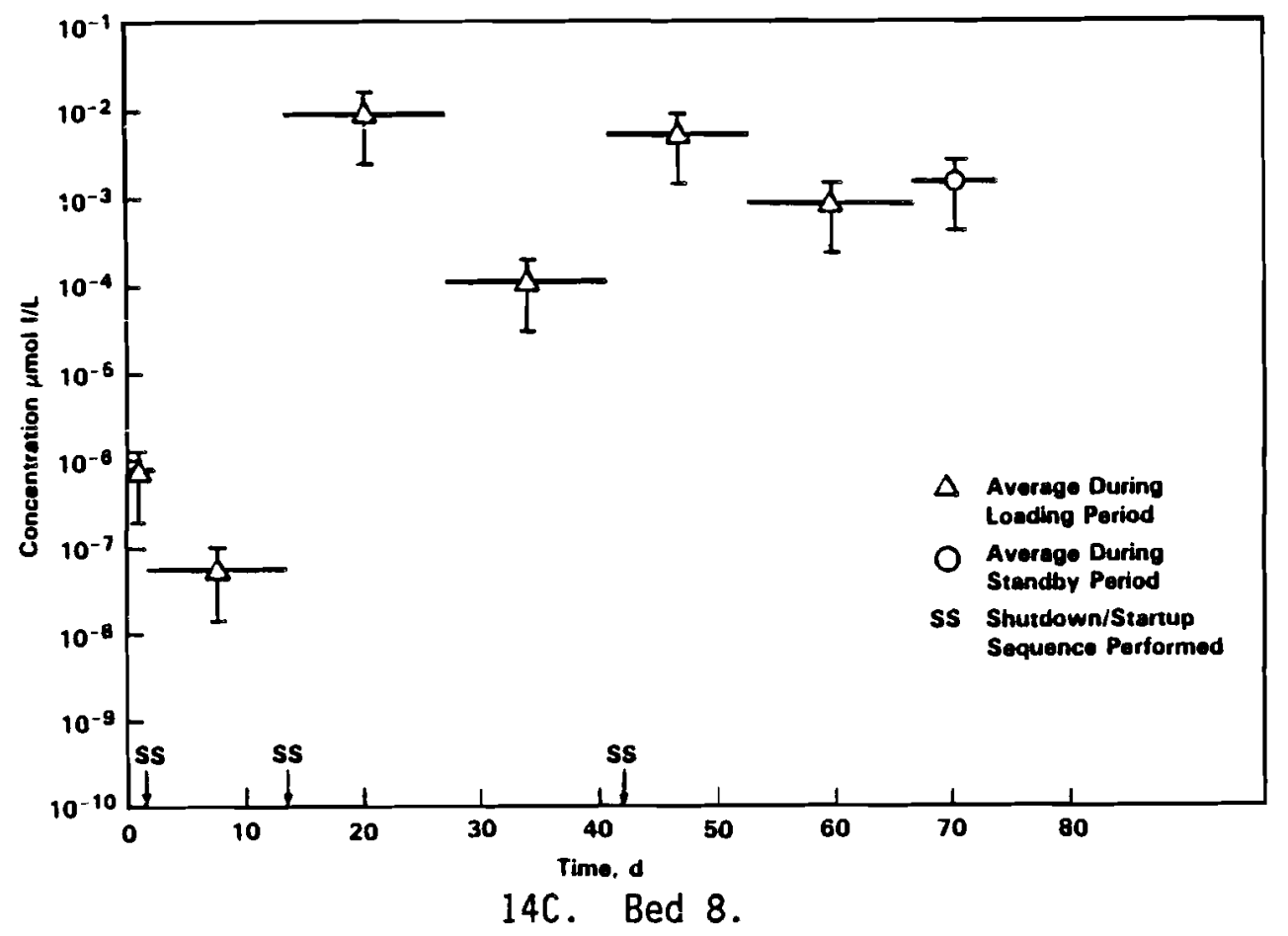

FIGURE 14. (contd)

startup cycle the effluent concentration increased from $10^{-7}$ to $10^{-2} \mu \mathrm{mol}$ I/L. Following the third shutdown/startup cycle, the effluent concentration increased less dramatically from $10^{-4}$ to $10^{-2} \mu \mathrm{mol} \mathrm{I} / \mathrm{L}$. These observed increases suggest that the shutdown/startup cycle causes a loss in trapping efficiency. However, these results are not conclusive and additional work would be required to confirm the observation. It is possible that water condensed in the $\mathrm{AgNO}_{3} \mathrm{Si}$, as it did in one of the $\mathrm{NAgZ}$ beds, but no condensed water was observed.

No explanation for this poor performance by silver nitrate-impregnated amorphous silicic acid has been determined. As Scheele, Burger and Matsuzaki (1983) discussed, the chemistry of the zeolite system with $\mathrm{NO}_{\mathrm{X}}$ present is quite complex. The ingredients present in the $\mathrm{AgNO}_{3} \mathrm{Si}$ material should be present in the silver zeolites exposed to the PFM DOG. The difference in trapping ability suggests that the substrate may be a significant factor in retaining iodine. Other factors that could influence iodine trapping and retention include pore size and the nature of the silver in the substrate. The mechanism of iodine trapping by silver-containing materials must be 
IABLE 5. Iodine Distribution on $\mathrm{AgNO}_{3} \mathrm{Si}$ Beds Before and After Standby Loading

\begin{tabular}{|c|c|c|c|c|}
\hline & & & \multirow{2}{*}{\multicolumn{2}{|c|}{ After Standby }} \\
\hline \multirow{2}{*}{$\begin{array}{c}\text { Segment, } \\
3.3 \mathrm{~cm} / \text { segment }\end{array}$} & \multicolumn{2}{|c|}{ Before Standby } & & \\
\hline & $\mathrm{mmol} \mathrm{I} / \mathrm{g}$ AgNO, $\mathrm{Si}$ & $\%^{(a)}$ & $\mathrm{mmol} \mathrm{I} / \mathrm{g} \mathrm{AgNO}, \mathrm{Si}$ & $\%^{(a)}$ \\
\hline
\end{tabular}
Bed 2

$0-3.3 \mathrm{~cm}$

$3.3-6.6 \mathrm{~cm}$

$6.6-9.9 \mathrm{~cm}$

$9.9-13.2 \mathrm{~cm}$

$13.2-16.5 \mathrm{~cm}$

$16.5-20.0 \mathrm{~cm}$

TOTAL

Bed 5

$0-3.3 \mathrm{~cm}$

$3.3-6.6 \mathrm{~cm}$

$6.6-9.9 \mathrm{~cm}$

$9.9-13.2 \mathrm{~cm}$

$13.2-16.5 \mathrm{~cm}$

$16.5-20.0 \mathrm{~cm}$

TOTAL

Bed 8

$0-3.3 \mathrm{~cm}$

$3.3-6.6 \mathrm{~cm}$

$6.6-9.9 \mathrm{~cm}$

$9.9-13.2 \mathrm{~cm}$

$13.2-16.5 \mathrm{~cm}$

$16.5-20.0 \mathrm{~cm}$

TOTAL
0.134

0.050

0.031

0.029

0.030

0.123

0.043

0.027

0.034

0.044

$\underline{0.025}$

0.296

0.153

0.035

0.024

0.028

0.029

$\underline{0.020}$

0.289

$\underline{0.019}$

0.293
$41.50 \pm 5.25$

0.149

$50.28 \pm 6.33$

$14.42 \pm 2.78$

0.042

$14.33 \pm 2.95$

$9.14 \pm 2.16$

0.023

$7.91 \pm 2.12$

$11.61 \pm 2.46$

0.028

$9.49 \pm 2.35$

$15.01 \pm 2.84$

0.032

$10.81 \pm 2.52$

$8.32 \pm 2.06$

$\underline{0.021}$

0.296

99.94

$7.12 \pm 2.01$

100.00

$53.10 \pm 4.90$

0.176

$60.85 \pm 6.00$

$12.09 \pm 2.00$

0.034

$11.67 \pm 2.19$

$8.26 \pm 1.62$

0.021

$7.22 \pm 1.69$

$9.66 \pm 1.77$

0.022

$7.58 \pm 1.73$

$9.88 \pm 1.79$

0.021

$7.31 \pm 1.70$

$7.01 \pm 1.49$

$\underline{0.015}$

$5.34 \pm 1.44$

0.289

99.97

100.00

$$
45.87 \pm 5.07
$$

0.154

$52.67 \pm 6.32$

$17.08 \pm 2.77$

0.048

$16.52 \pm 3.09$

$10.46 \pm 2.10$

0.028

$9.42 \pm 2.26$

$9.88 \pm 2.04$

0.024

$8.15 \pm 2.09$

$10.17 \pm 2.07$

0.024

$8.06 \pm 2.07$

$6.53 \pm 1.63$

$\underline{0.015}$

$\underline{5.22 \pm 1.65}$

(a) $95 \%$ confidence level based on counting statistics. 
further understood before this difference in performance can be understood. The performance of the $\mathrm{AgNO}_{3} \mathrm{Si}$ material emphasizes the need for studies that would increase our understanding of the mechanism for trapping and retaining iodine by silver sorbents.

The as-received $\mathrm{AgNO}_{3} \mathrm{Si}$ was predominately white spherical beads, with some light-to-dark gray beads at room temperature and at $150^{\circ} \mathrm{C}$. When iodine began loading on the beds, the $\mathrm{AgNO}_{3} \mathrm{Si}$ turned yellow. After the first shutdown/startup cycle, beds 2 and 8 turned white and remained white for the remainder of the experiments. Bed 5 developed a $5 \mathrm{~cm}$ wide yellow band that gradually spread down one side for $15 \mathrm{~cm}$.

Based on these studies, the $\mathrm{AgNO}_{3} \mathrm{Si}$ did not meet the target concentration of $10^{-5} \mu \mathrm{mol} \mathrm{I} / \mathrm{L}$, and would not be an acceptable sorbent material for application in the PFM.

\section{PRESSURE DROP}

During these experiments the pressure drops $(\Delta P)$ across each bed were measured almost daily to determine the possible effects on the physical properties of the test beds as a result of loading with iodine, exposure to the highly acidic DOG, and exposure to the shutdown/startup cycle. It would be unacceptable if, during actual application in the PFM, the material were to degrade, lose its particulate nature, and subsequently restrict gas flow. One of the criteria that has been used for recommending AgZ over AgX is the susceptibility of AgX to attack by an acidic environment at room temperature. This susceptibility has been observed in our laboratory and was discussed in Scheele and Burger (1987).

As shown in Table 6 , there were no major changes in $\Delta P$ across the different beds during the experiments, although enough variability existed to make it uncertain whether real changes occurred over the experiment. There is, however, some indication that the $\triangle P$ s across the LAgZ beds increased with time. The degree of change observed for the NAgZ beds was greatest for bed 4 (24 to $50 \mathrm{~mm} \mathrm{Hg}$ ). No change occurred for bed 7 . The increase in $\Delta \mathrm{P}$ for bed 4 was observed after the first shutdown/startup cycle, when bed 4 flooded with water. The increase observed for bed 1 occurred later in the experiment, and the reason for the increase is not apparent. 
TABLE 6. Pressure Drop Across Test Beds

\begin{tabular}{|c|c|c|c|c|c|}
\hline \multirow[b]{2}{*}{ Bed } & \multicolumn{5}{|c|}{ Pressure Drop $(\Delta P)(a)(b), m m ~ H g$} \\
\hline & Day 0 & Day 6 & Day 18 & Day 46 & Day 67 \\
\hline $1-\mathrm{NAgZ}$ & 30 & 27 & 31 & 45 & 44 \\
\hline $2-\mathrm{AgNO}_{3} \mathrm{Si}$ & 10 & 7 & 10 & 17 & 14 \\
\hline $3-\operatorname{Ag} X$ & 18 & 13 & 16 & 21 & 22 \\
\hline 4-NAgZ & 24 & 51 & 40 & 52 & 40 \\
\hline $5-\mathrm{AgNO}_{3} \mathrm{Si}$ & 16 & 9 & 10 & 14 & 13 \\
\hline $6-\operatorname{Ag} X^{2}$ & 17 & 17 & 14 & 24 & 21 \\
\hline 7-NAgZ & 29 & 34 & 30 & 36 & 30 \\
\hline $8-\mathrm{AgNO}_{3} \mathrm{Si}$ & 8 & 18 & 10 & 16 & 16 \\
\hline 9-LAgZ & 21 & 24 & 20 & 27 & 24 \\
\hline Flow, $\mathrm{mL} / \min (\mathrm{c})$ & 380 & 315 & 325 & 373 & 353 \\
\hline Face Velocity, m/min & 4.8 & 4.0 & 4.1 & 4.8 & 4.5 \\
\hline
\end{tabular}

(a) $\mathrm{T}=150^{\circ} \mathrm{C}$, Dia. $=1 \mathrm{~cm}$, Length $=20.0 \mathrm{~cm}$ except Bed 2 and Bed $8=19.5 \mathrm{~cm}$.

(b) $\mathrm{AgNO}_{3} \mathrm{Si}$ is $1.6 \mathrm{~mm}$ dia. beads; remainder are $-20+40$ mesh

(c) Measured at $23^{\circ} \mathrm{C}$

The AgX exhibits the same degree of chemical stability as NAgZ and LAgZ when exposed to the acidic gases of a simulated PFM DOG at $150^{\circ} \mathrm{C}$. It is likely that the high temperature of operation, $150^{\circ} \mathrm{C}$, prevented condensation of a sufficient amount of water to form a highly corrosive nitric or nitrous acid solution in the pores of the zeolite. This apparent acid resistance suggests that $\mathrm{AgX}$ could also serve as a sorbent for gaseous iodine present in the DOG of the PFM. Before using AgX in a plant environment, it would be wise to test the material for its projected useful lifetime.

When the pressure drop data for day 67 are normalized to account for bed diameter, length, and temperature, there is good agreement with results previously obtained at this laboratory (Scheele and Burger 1987).

The lack of any progressive changes in the observed $\triangle \mathrm{Ps}$ across each of the bed materials indicates that loading with iodine, exposure to the acidic 
gases of the PFM DOG, and exposure to repeated shutdown/startup cycles will not affect the physical integrity of the sorhent materials. 


\section{QUALITY ASSURANCE TESTING OPTIONS}

Since the mechanism for trapping iodine on silver sorbents is not comipletely understood, it is difficult to provide descriptive specifications for purchasing appropriate material. Easily determined specifications include the material type, the extent of silver substitution, the mesh size and distribution, and the form (e.g., beads or pellets). However, choosing material based only on those criteria does not guarantee adequate performance; laboratory tests must be conducted on the material. Reasonable purchase specifications would include material or zeolite type, form, mesh (range), and silver content. Laboratory tests should include chemical analysis to confirm the purchase specifications and a test for iodine sorption efficiency. Chemical analysis can be done by inductively coupled plasma (ICP) atomic absorption spectroscopy, which in addition to silver would give the silicon-to-aluminum ratio and an indication of impurities.

Laboratory testing to determine iodine sorption efficiency poses a much more difficult problem. The most effective approach would be to load a sample of the sorbent under process conditions and examine both the effluent gas concentration and the loading level.

An alternative approach involves loading the zeolite from the gas phase. A sample of sorbent, conditioned in air at $150^{\circ} \mathrm{C}$, would be sealed in a glass vessel with $100 \mathrm{mg}$ of $\mathrm{I}_{2}$ per gram of silver sorbent. The vessel would then be evacuated and heated for 48 hours, opened to the atmosphere, purged with air, and cooled. X-ray fluorescence would then be used to analyze the iodine-containing sorbent sample for iodine content. The mass change would also be recorded. Thermal analysis, thermogravimetry and differential scanning calorimetry of the loaded sample could be used to obtain more detailed information.

Another alternative involves a simple test loading from the liquid phase. The silver sorbent could be placed in a small column (e.g., $10 \mathrm{~g}$ of sorbent in a $1 \mathrm{~cm} \mathrm{dia.} \mathrm{tube)} \mathrm{and} 1 \mathrm{~g}$ of iodine dissolved in an inert organic solvent would then be passed through the bed in a controlled, slow fashion. 
The effluent would be tested for iodine concentration. To implement this test, laboratory testing would be needed to pick the best solvent and optimize the genmetry and flow rates. Another iess desirable method of doing this test would be to stir or shake a quantity of silver sorbent with the iodine-containing solvent. It is probable that a test loading from the liquid phase can be designed to give important information on the quality of the sorbent.

Before applying these tests or similar tests, it would be necessary to develop the test and evaluate it using materials that are effective, partially effective, or ineffective iodine traps.

Finally, if a research program is undertaken to provide the basic information needed to understand the mechanism of iodine trapping on silver sorbents (e.g., thermal analysis, structure studies, species identification, kinetics, and thermodynamic calculations), it is quite likely that better and perhaps simpler specifications or quality assurance tests can be devised. 


\section{IODINE MONITORING}

To monitor the performance of the gaseous radioiodine control system in the PFM or in any type of fuel reprocessing plant, it is necessary to monitor the concentration of radioiodine in the exit gas. Changing out the first sorbent bed at the proper time is also determined by monitoring the concentration of iodine in the first bed's effluent. No real-time monitor exists for ${ }^{129}$ I (Scheele, Burger, and Soldat 1984), so a sampler based on iodine trapping must be used to accumulate sufficient radioiodine to measure.

Potential iodine traps include caustic scrubbers and the silvercontaining sorbents. Bubblers using sodium hydroxide solution are often used for trapping halogen gases. We prefer $36 \mathrm{wt} \%$ silver, silver-substituted faujasite (AgX) contained in a glass tube heated to $150^{\circ} \mathrm{C}$. The AgX material has been demonstrated to efficiently trap gaseous iodine. If this method were used, the contents could be counted periodically in a NaI(TI) well counter to determine the ${ }^{129} \mathrm{I}$. An added advantage of using AgX is that the top 1 to $2 \mathrm{~mm}$ of the bed becomes yellow when the material has sorbed significant quantities of iodine, thus allowing the operator to see that a large amount of iodine exists in the exit gas.

A1though the lower limit for ${ }^{129}$ I detection by counting (gamma and $x$-rays) may be in the vicinity of $10^{-7}$ to $10^{-8} \mu \mathrm{C} i$, a practical routine 1 aboratory 1 imit for iodine on zeolite may be two orders of magnitude greater (e.g., $10^{-5} \mu \mathrm{Ci}$ or $4.5 \times 10^{-4} \mu \mathrm{mol}$ ). Thus, a sampler tube operating at $500 \mathrm{~mL} / \mathrm{min}$ for $90 \mathrm{~min}$ would detect $10-5 \mu \mathrm{mol} / \mathrm{L}$. An 8 -h sample time should give a reliable measurement. The amount of AgX used in the sampler can be adjusted for the counter used; for example, 5 to $15 \mathrm{~g}$ of $-20+40$ mesh AgX could be used in a $1 \mathrm{~cm} \mathrm{I.D.} \mathrm{column,} \mathrm{and} \mathrm{a} \mathrm{high} \mathrm{recovery} \mathrm{factor} \mathrm{would} \mathrm{still}$ be possible.

In a radioiodine control system with a second sorbent bed in place, there would be no danger of iodine release even if the level from the first bed exceeds $10^{-5} \mu \mathrm{mol} \mathrm{I} / \mathrm{L}$ during the sample period. 

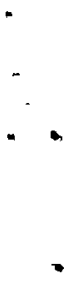


\section{REFERENCES}

Burger, L. L. and R. D. Scheele. 1983. The Status of Radioiodine Control for Nuclear Fuel Reprocessing Plants. PNL-4689, Pacific Northwest Laboratory, Richland, Washington.

McKay, H. A. C., P. Mique1, and I. F. White. 1982. "Management Modes for Iodine-129." In Management Modes for Iodine-129, eds. W. Hebel and G. Cottone. Harwood Academic Publishers, New York, New York.

Scheele, R. D. and L. L. Burger. 1987. Evaluation of Silver Mordenite for Radioiodine Retention at the PUREX Process Facility Modification. PNL-6261, Pacific Northwest Laboratory, Richland, Washington.

Scheele, R. D., L. L. Burger, and C. L. Matsuzaki. 1983. Methyl Iodide Sorption by Reduced Silver Mordenite. PNL-4489, Pacific Northwest Laboratory, Richland, Washington.

Thomas, T. R., L. P. Murphy, B. A. Staples, and J. T. Nichols. 1977. Airborne Elemental Iodine Loading Capacities of Metal Zeolites and A Method for Recycling Silver Zeolite. ICP-1119, Idaho National Engineering Laboratory, Idaho Falls, Idaho. 


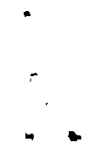

. 


\section{DISTRIBUTION}

No. of

Copies

OFFSITE

10 DOE/Office of Scientific and Technical Information

Exxon Nuclear Idaho

P.0. Box 2800

Idaho Falls, ID 83401

ATTN: R. A. Brown

J. D. Christian

T. R. Thomas

J. Fürrer

Karlsruhe Nuclear Center

7500 Karlsruhe

FEDERAL REPUBLIC OF GERMANY

R. T. Jubin

Oak Ridge Nationai Laboratory P.0. Box X

Oak Ridge, TN 37830

D. F. Torgerson

Whiteshel1 Nuclear Research Establ ishment

Atomic Energy of Canada

Pinawa, Manitoba, CANADA

\section{ONSITE}

3 DOE-Richland Operations

J. D. Furubotten (2)

J. J. Sutey

23 Westinghouse Hanford Company

D. E. Ball

G. L. Borsheim

D. R. Bratzel

C. R. Cawley

G. E. Coulter

D. A. Dodd

E. W. Harris
No. of

Copies

Westinghouse Hanford Company

D. L. Herting

J. P. Hinckley

K. N. Jordan

E. J. Kosiancic

R. E. Lerch

W. F. Nicaise

R. M. Orme

K. E. Plummer

G. W. Reddick

D. A. Reynolds

R. C. Roal

D. E. Scul1y

W. W. Schulz

J. A. Swenson

D. J. Washenfelder

E. D. Waters

Pacific Northwest Laboratory

W. F. Bonner

K. A. Borgeson

D. J. Bradley

F. P. Brauer

L. A. Bray

L. L. Burger (2)

R. W. Goles

E. J. Kaiser

R. S. Kemper

L. T. Lakey

J. W. Latkovich

J. L. McElroy

A. M. Platt

W. A. Ross

L. J. Sealock

R. D. Scheele (10)

J. K. Soldat

J. L. Straal sund

J. L. Swanson

P. C. Walkup

E. J. Wheelwright

Publishing Coordination (2)

Technical Report Files (5) 


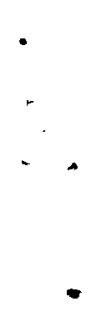

